El Sistema Nacional de Vigilancia en Salud Pública - SIVIGILA, realiza de forma rutinaria un monitoreo de los eventos de Arbovirus, de este grupo, los eventos con la mayor incidencia estimada en Colombia son dengue, chikungunya y zika, esta condición dada por las características geográficas del país, las condiciones de transmisión de los virus y la presencia del vector en la mayoría de los municipios.

A semana epidemiológica 40 de 2020, el evento de dengue aporta el 99,5\% de la notificación de Arbovirus a nivel nacional, con 70577 casos notificados para una incidencia de 263,8 casos por 100000 habitantes. Según el comportamiento epidemiológico, durante el primer trimestre del 2020, el evento de dengue se ubicó por encima del límite superior esperado, situación que correspondía a la continuación del ciclo epidémico del evento a nivel nacional que inició en la semana epidemiológica (SE) 08 de 2019. A partir de la SE 12 de 2020, a nivel nacional se observa un descenso continuo en la notificación situación que coincide a su vez con la contingencia de COVID-19 a nivel nacional, ubicándose en situación de alerta entre la SE 12 y SE 20, y a partir de la SE 21 se ubica en situación dentro de lo esperado (figura 1).

Figura 1. Cobertura de vacuna de DPT3 vs TdaP vs incidencia vs letalidad, 2008-2019, Colombia

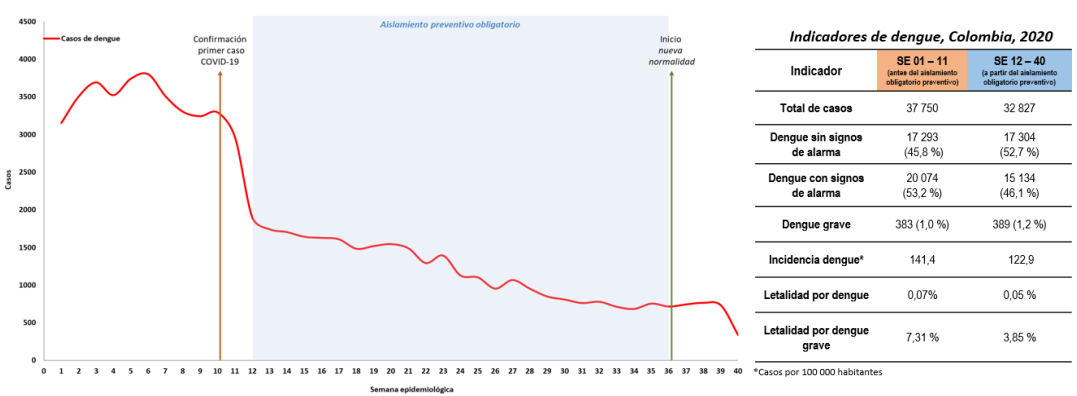

Fuente: Instituto Nacional de Salud - Grupo ETV - Zoonosis.

Por entidad territorial, Valle del Cauca, Cali, Huila, Tolima, Santander, Cundinamarca, Meta, Antioquia, Cesar, Caquetá, Córdoba y Sucre aportan el 81,1 \% (57 250) de los casos a nivel nacional (semana epidemiológica 40 de 2020). De acuerdo del comportamiento epidemio- lógico, Caldas, Cauca, Chocó, Nariño y Valle del Cauca se mantienen en situación de brote para dengue: Por otra parte, según el análisis de las poblaciones priorizadas, en el periodo epidemiológico X (SE: 37 - 40), se observan incrementos en la notificación de dengue en menores de 5 años en Córdoba, Sucre, Norte de Santander, Santander, Cundinamarca, Tolima, Caquetá y Cali; mientras que, en la notificación de dengue en mayores de 65 años se observan incrementos en Antioquia, Sucre, Santander, Casanare, Huila y Quindío (figura 2).

Figura 2. Comportamientos inusuales de dengue por entidad territorial, Colombia, periodo epidemiológico X, 2020
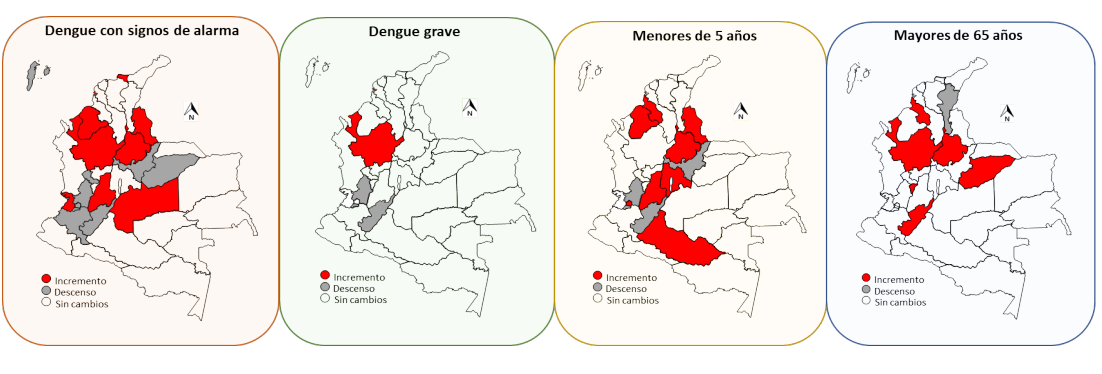

Nota: Comparación con el periodo epidemiológico IX, 2020

Fuente: Instituto Nacional de Salud - Grupo ETV - Zoonosis.

A semana epidemiológica 40 de 2020, se han confirmado 43 casos de mortalidad por dengue, para una letalidad por dengue grave de 5,6\%, inferior a lo registrado entre 2012 a 2019. Con respecto al análisis del tablero de problemas con corte a semana epidemiológica 34 de 2020, en las muertes confirmadas para dengue se identificaron 189 problemas, el $76,3 \%$ se relacionaron con la Institución prestadora de salud, el $8,4 \%$ con la Entidad Administradora de Planes de Beneficios (EAPB), el 8,2 \% con la Entidad territorial y el 7,1\% con otros actores. De acuerdo con la categoría de problemas, los principales inconvenientes identificados fueron: el incumplimiento a las guías de atención, incumplimiento en las estrategias de comunicación del riesgo, Demora en el traslado por trámites administrativos y, baja percepción del riesgo para el acceso oportuno y continuo a los servicios de salud. Se identificaron en promedio 3,87 problemas por cada muerte y, por entidad territorial, el 60,8\% de los problemas se concentraron en los departamentos de Valle del Cauca, Cauca y Huila. 
Figura 3. Problemas de mayor impacto por categoría de problemas en mortalidades por dengue, Colombia, a semana 34, 2020.

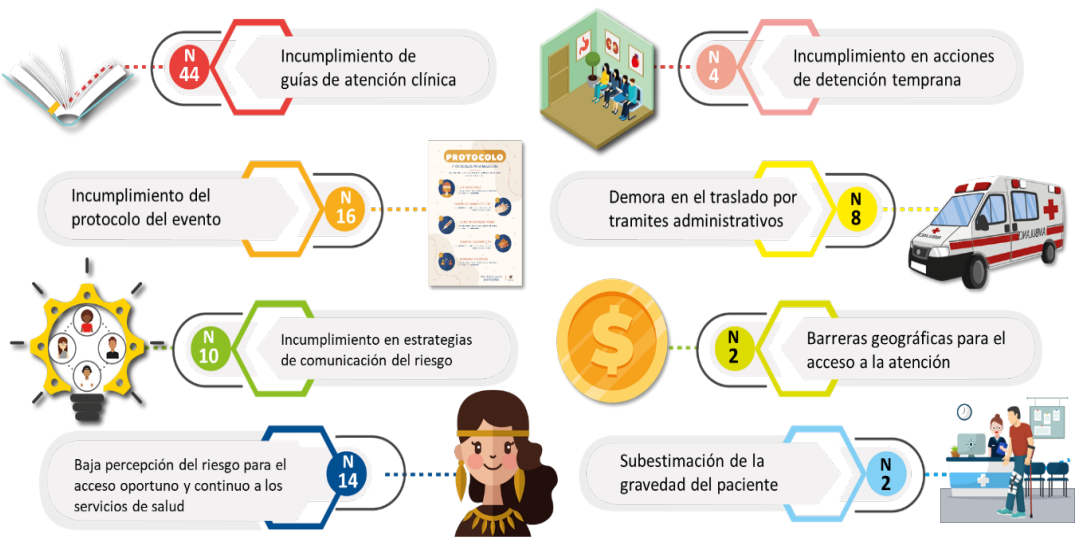

Fuente: Instituto Nacional de Salud - Grupo de Análisis de casos especiales.

A semana epidemiológica 40 de 2020, se notificaron 156 casos de chikungunya y 160 casos de enfermedad por virus Zika, para una incidencia nacional de 0,5 casos por 100000 habitantes cada uno. En los últimos años se observa un descenso gradual en la notificación al Sistema Nacional de Vigilancia en Salud Pública de estos eventos, ubicándose en este año por debajo del límite inferior esperado. Por entidad territorial, en el periodo epidemiológico X de 2020, Boyacá y Caquetá presentan un incremento significativo de enfermedad por virus Zika, mientras que las demás entidades presentan un descenso o no hay cambios con respecto a lo esperado.

Figura 4. Comportamientos inusuales de Chikungunya y enfermedad por virus Zika por entidad territorial, Colombia, periodo epidemiológico X, 2020
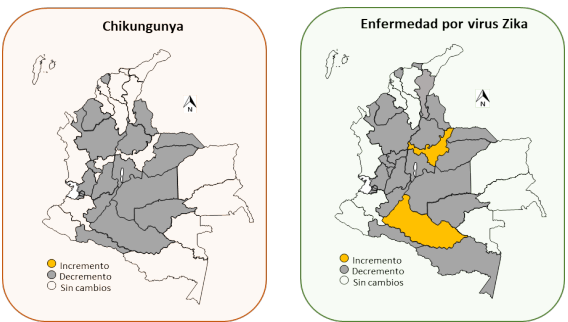

Fuente: Instituto Nacional de Salud - Grupo ETV - Zoonosis.

\section{Vigilancia virológica}

Mediante la vigilancia por el Laboratorio de virología del Instituto Nacional de Salud, durante el 2020 se ha identificado la circulación de DENV 1, 2 y 3 en Barranquilla, Bolívar, Cesar, La Guajira, Meta, Putumayo, Risaralda, Tolima y Valle del Cuaca, mientras que en 21 entidades territoriales se aisló 1 o 2 serotipos del virus. Por otro lado, no se ha detectado circulación de virus Chikungunya en las muestras analizadas, pero si virus Zika en muestras de suero de casos procedentes de Antioquia, Caquetá, Norte de Santander y Valle del Cauca; (tabla 1).

Tabla 1. Circulación de serotipos del virus Dengue, virus Chikungunya y Zika. Colombia, a semana epidemiológica 40 de 2020

\begin{tabular}{|c|c|c|c|c|c|c|}
\hline \multirow{2}{*}{\multicolumn{7}{|c|}{$\begin{array}{l}\text { Entidad territorial } \\
\text { Amazonas }\end{array}$}} \\
\hline & & & & & & \\
\hline Antioquia & & & & & & 0 \\
\hline Arauca & & & & & & \\
\hline Atlántico & & 0 & & & & \\
\hline Barranquilla & & 0 & 0 & & & \\
\hline Bolivar & & 0 & 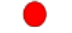 & & & \\
\hline Boyacá & & 0 & & & & \\
\hline Caquetá & & & & & & 0 \\
\hline Casanare & & & & & & \\
\hline Cauca & & 0 & & & & \\
\hline Cesar & 0 & 0 & 0 & & & \\
\hline Chocó & & & & & & \\
\hline Córdoba & & & & & & \\
\hline Cundinamarca & & & & & & \\
\hline Huila & & 0 & & & & \\
\hline La Guajira & & 0 & O & & & \\
\hline Magdalena & & & & & & \\
\hline Meta & & 0 & 0 & & & \\
\hline Narino & & & & 0 & & \\
\hline Norte de Santander & & & & & & 0 \\
\hline Putumayo & & 0 & 0 & & & \\
\hline Quindio & 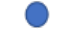 & & & & & \\
\hline Risaralda & 0 & 0 & 0 & & & \\
\hline Santander & 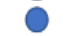 & & & & & \\
\hline Sucre & & & 0 & & & \\
\hline Tolima & 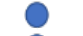 & 0 & - & & & \\
\hline Valle del Cauca & ○ & 0 & 0 & & & 0 \\
\hline Vichada & & & & & & \\
\hline $\begin{array}{l}\text { Departamento sin } \\
\text { establecer }\end{array}$ & 0 & 0 & & & & 0 \\
\hline
\end{tabular}

Nota: En esta tabla se incluyen solamente las Entidades territoriales que tienen confirmación de la circulación viral de DENV, CHIKV o ZIKV Fuente: Instituto Nacional de Salud. LNR Virología
Tema centra

Situación Nal.

Mortalidad

Trazadores

Brotes

COVID-19 


\section{Recomendaciones}

A las entidades territoriales:

- Fortalecer la socialización de guías, lineamientos, protocolos y circulares de los Arbovirus con el fin de garantizar el manejo integral de los casos, el diagnóstico diferencial con otros síndromes febriles y el cumplimiento de los indicadores de vigilancia en Salud Pública.

- Dar regularidad al trabajo intersectorial y fortalecer las estrategias de promoción, prevención y control en conjunto para dengue, chikungunya y zika.

- Mantener el monitoreo de comportamientos inusuales y generación de alertas a nivel municipal de dengue con signos de alarma, dengue grave, menores de 5 años y mayores de 65 años.

\section{SITUACIÓN NACIONAL}

\section{Tablero de control del análisis de datos de la vigilancia}

Para el análisis de los eventos de mayor notificación en el país, se compara el valor observado en la semana epidemiológica correspondiente, con una línea de base de referencia, que está conformada con la información de esos eventos reportados en 15 intervalos de tiempo de al menos cinco años anteriores.

Se identifica que en la semana epidemiológica 41, el evento de infección respiratoria aguda grave IRAG se encuentra por encima de los valores esperados, mientras que los eventos de malaria, parotiditis, mortalidad perinatal y neonatal tardía, leishmaniasis cutánea, bajo peso al nacer, intoxicaciones, agresiones por animales potencialmente trasmisores de rabia (APTR) y varicela se encuentran por debajo de sus valores esperados. Los demás eventos están dentro del comportamiento histórico de la notificación (Figura 5).

Figura 5. Comparación de la notificación de casos de eventos priorizados, de alta frecuencia, según su comportamiento histórico. Colombia, semana epidemiológica 41 de 2020

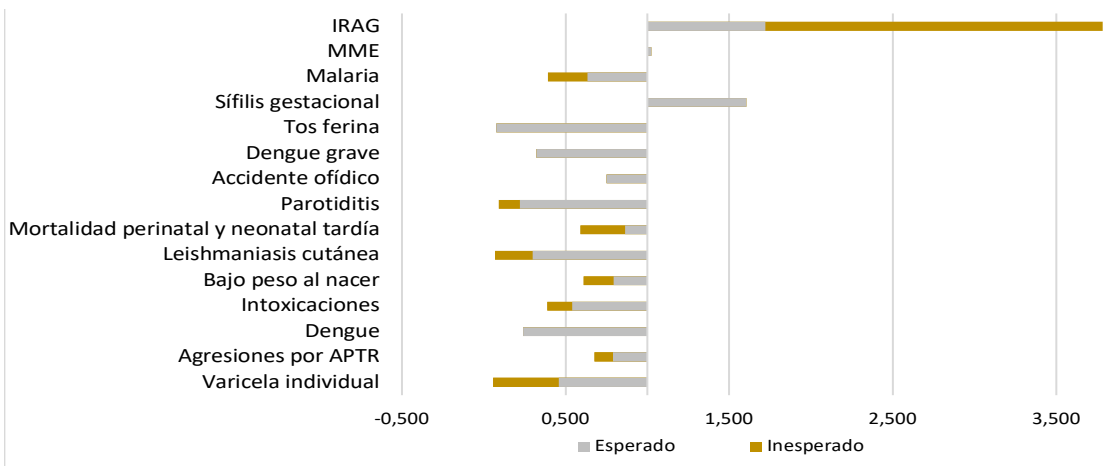

Fuente: Sivigila, Instituto Nacional de Salud, Colombia, 2020
Tema centra

Situación $\mathrm{Nal}$

Mortalidad

Trazadores

Brotes

COVID-19

Tablas 
Para el análisis de los eventos de baja frecuencia o raros, se comparan los casos observados y los esperados según su comportamiento histórico. Se calcula la probabilidad de la significación estadística de la comparación. Valores menores a 0,06 en la columna "Poisson" indican que existe una diferencia significativa entre lo observado y lo esperado para la semana analizada.

Los eventos de sarampión, síflis congénita, leptospirosis y lepra presentan una disminución significativa relacionada con el comportamiento de notificación histórico. Los demás eventos se encuentran dentro del comportamiento histórico establecido (Tabla 2).

Tabla 2. Comparación de casos notificados de eventos priorizados, de baja frecuencia, según su comportamiento histórico, Colombia, semana epidemiológica 41 de 2020

Evento
Síflis congénita
ESAVI

Sarampión

Leptospirosis

Rubeola

Mortalidad por IRA

Lepra

Tuberculosis fármacorresistente

Mortalidad materna

Fiebre tifoidea y paratifoidea

Mortalidad por dengue

Mortalidad por EDA 0-4 Años

Leishmaniasis mucosa

Observado

Esperado

Poisson

intente

Fuente: Sivigila, Instituto Nacional de Salud, Colombia, 2020

\section{Cumplimiento en la notificación}

Para esta semana la notificación recibida por el Instituto Nacional de Salud correspondiente a las unidades notificadoras departamentales y distritales (UND) fue del $100 \%$, permaneció igual tanto para la semana anterior como para la misma semana del 2019. El país cumplió con la meta establecida para UND.
El reporte de las unidades notificadoras municipales (UNM) a nivel nacional fue $100 \%$ (1 117/ 1117 UNM), permaneció igual tanto para la semana anterior y también como para la misma semana de 2019. El país cumplió con la meta del $97 \%$ en la notificación de UNM.

El cumplimiento de las Unidades Primarias Generadoras de Datos (UPGD) esta semana fue de 97,1 \% (4 866 / 5007 UPGD); disminuyo $0,3 \%$ frente a la semana anterior del presente año y $0,7 \%$ con respecto a la misma semana de 2019.

El país cumplió con la meta para la notificación de UPGD, en la gráfica se refleja con la línea verde que es el porcentaje de notificación de la presente semana; la línea amarilla representa el número mínimo de UPGD que debe notificar (meta $90 \%$ ) y la línea azul evidencia la red actual, un total de 5007 UPGD caracterizadas (Figura 6).

Figura 6. Cumplimiento de la notificación por UPGD, Colombia, semanas epidemiológicas 35 a 41 de 2020

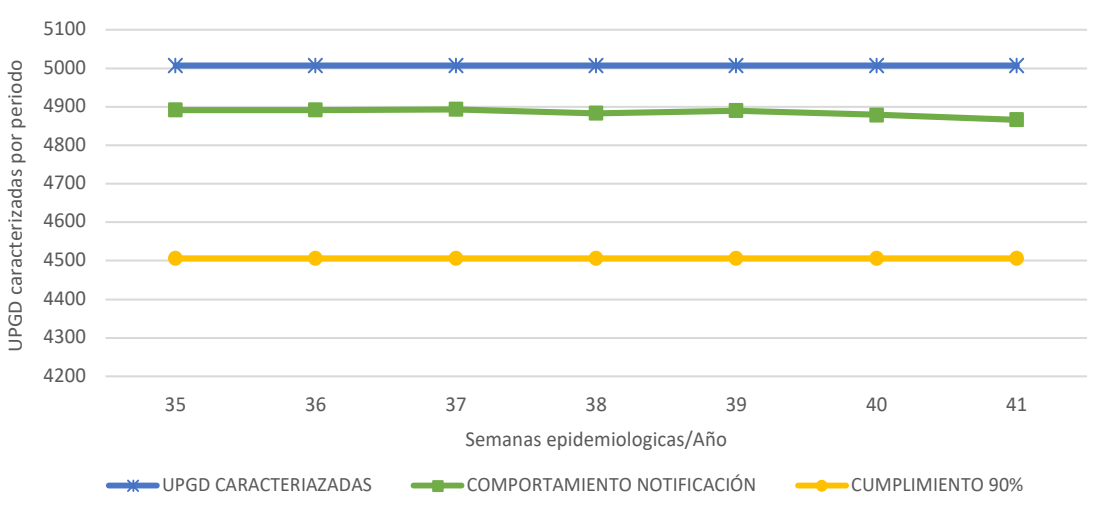

Fuente: Sivigila, Instituto Nacional de Salud, Colombia, 2020
Tema centra

Situación Nal.

Mortalidad

Trazadores

Brotes

COVID-19

Tablas 


\section{MORTALIDAD}

Mortalidad en menores de 5 años por eventos priorizados, semana epidemiológica 41 de 2020

Esta semana se notificaron 10 muertes en menores de 5 años: 7 probablemente asociadas a infección respiratoria aguda, 1 a desnutrición y 2 a enfermedad diarreica aguda.

\section{Mortalidad por infección respiratoria aguda}

Se notificaron 7 muertes por infección respiratoria aguda en menores de 5 años, 4 de esta semana y 3 correspondientes a semanas anteriores. Para la misma semana de 2019 se notificaron 3 casos.

Para esta semana se observó una disminución en el número de casos, en comparación con el histórico notificado en el mismo periodo 2014 a 2019 en las entidades territoriales de Antioquia, Bogotá, Bolívar, Caldas, Cartagena, Cesar, Cundinamarca y La Guajira mientras que, en los departamentos de Huila, Boyacá y Norte de Santander se observó un aumento. En las entidades territoriales restantes no se presentaron variaciones (Figura 7).

Figura 7. Entidades Territoriales con variaciones significativas respecto al promedio de casos notificados por mortalidad por infección respiratoria aguda, 2014 a 2019, Colombia, semana epidemiológica 41 de 2020*

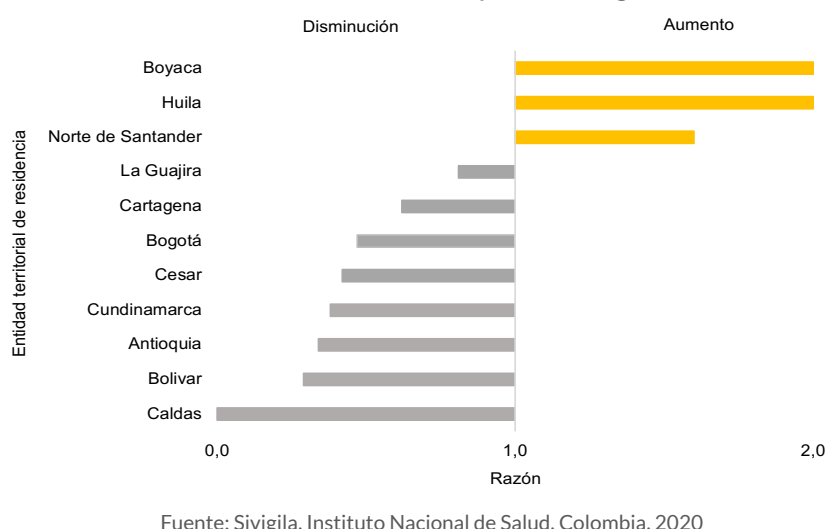

\section{Mortalidad por enfermedad diarreica aguda}

Se notificaron 2 muertes por enfermedad diarreica aguda en menores de 5 años. Para la misma semana de 2019 se notificaron 2 casos.

Para esta semana se observó un aumento en el número de casos en comparación con el histórico notificado en el mismo periodo 2014 a 2019 en los departamentos de La Guajira y Santa Marta mientras que, en los departamentos de Antioquia y Chocó se observó una disminución. En las entidades territoriales restantes no se observaron variaciones.

\section{Mortalidad por desnutrición}

Se notificó 1 muerte en menores de 5 años probablemente asociada a desnutrición. Para la misma semana de 2019 se notificó 1 caso.

Para esta semana se observó un aumento en el número de casos en comparación con el histórico notificado en el mismo periodo 2014 a 2019 en las entidades territoriales de Atlántico y Barranquilla mientras que, en los departamentos de Bogotá, Cesar, Caquetá, Chocó, Córdoba, Guaviare, Huila y Vichada se observó una disminución. En las entidades territoriales restantes no se observaron variaciones.

*Para el análisis de los datos se tomó el comportamiento de cada uno de los eventos a semana epidemiológica 41 entre 2014 a 2019 (histórico) y se comparó con los casos observados a la misma semana epidemiológica del 2020. La razón esperada siempre será 1 y la significancia estadística estará dada por el valor de $\mathrm{p}<0,05$ para identificar las entidades territoriales que presentan variaciones estadísticamente significativas.

\section{Mortalidad materna}

A semana epidemiológica 41 del 2020 se notificaron 446 muertes maternas: 323 tempranas (ocurridas durante el embarazo, parto y hasta los 42 días de terminada la gestación), 108 tardías (ocurridas desde el día 43 hasta un año de terminada la gestación) y 15 por causas coincidentes (lesiones de causa externa); se presenta un aumento del 39,2\% en el número de muertes maternas respecto al 2019 (Tabla 3).
Tema central

Situación $\mathrm{Nal}$

Mortalidad

Trazadores

Brotes

COVID-19

Tablas 
Tabla 3. Mortalidad materna según tipo de muerte, Colombia, semanas epidemiológicas 01 a 41, años 2018 a 2020

\begin{tabular}{ccccc} 
& \multicolumn{3}{c}{ Tino de muerte } & Total \\
\cline { 2 - 4 } & Temprana & Tardía & Coincidente & \\
2018 & 224 & 137 & 65 & 426 \\
2019 & 232 & 115 & 51 & 398 \\
2020 & 323 & 108 & 15 & 446 \\
\hline & Fuente: Sivigila, Instituto Nacional de Salud, Colombia, 2018-2020
\end{tabular}

La razón nacional preliminar de mortalidad materna a semana epidemiológica 41 es de 61,8 muertes por cada 100000 nacidos vivos. La razón de mortalidad materna superior a 100 muertes por cada 100000 nacidos vivos se observó en las entidades territoriales de Amazonas, Chocó, Vaupés, La Guajira, Putumayo, Magdalena, Guainía y Caquetá (Tabla 4).

Tabla 4. Razón de mortalidad materna según entidad territorial de residencia, Colombia, semanas epidemiológicas 01 a 41 de 2020

\begin{tabular}{|c|c|c|}
\hline $\begin{array}{l}\text { Entidad territorial de } \\
\text { residencia }\end{array}$ & Número de casos & $\begin{array}{c}\text { Razón de MM por } 100000 \\
\text { nacidos vivos }\end{array}$ \\
\hline Amazonas & 3 & 317,1 \\
\hline Chocó & 10 & 227,9 \\
\hline Vaupés & 1 & 200,4 \\
\hline La Guajira & 31 & 170,5 \\
\hline Putumayo & 5 & 137,3 \\
\hline Magdalena & 16 & 136,2 \\
\hline Guainía & 1 & 133,0 \\
\hline Caquetá & 6 & 104,1 \\
\hline Atlántico & 15 & 93,1 \\
\hline Santa Marta & 8 & 92,9 \\
\hline Barranquilla & 16 & 83,0 \\
\hline Casanare & 4 & 82,7 \\
\hline Cundinamarca & 24 & 82,3 \\
\hline Vichada & 1 & 82,2 \\
\hline Córdoba & 16 & 78,0 \\
\hline Buenaventura & 3 & 77,4 \\
\hline Cauca & 11 & 76,5 \\
\hline Meta & 9 & 74,1 \\
\hline Sucre & 9 & 73,3 \\
\hline Norte de Santander & 13 & 67,8 \\
\hline Bolívar & 9 & 65,9 \\
\hline Nariño & 9 & 65,6 \\
\hline Colombia & 323 & 61,8 \\
\hline Caldas & 4 & 58,8 \\
\hline Cartagena & 8 & 52,3 \\
\hline Cesar & 9 & 47,8 \\
\hline Cali & 9 & 45,0 \\
\hline Santander & 9 & 39,5 \\
\hline Valle del Cauca & 6 & 38,2 \\
\hline Antioquia & 23 & 37,8 \\
\hline Risaralda & 3 & 36,5 \\
\hline Boyacá & 4 & 36,1 \\
\hline Bogotá & 22 & 31,0 \\
\hline Arauca & 1 & 26,3 \\
\hline Tolima & 3 & 22,8 \\
\hline Quindío & 1 & 22,3 \\
\hline Huila & 1 & 7,0 \\
\hline
\end{tabular}

Para la semana epidemiológica 40 de 2020 se observó un aumento significativo en las muertes maternas tempranas comparado con el promedio histórico en las entidades territoriales de Atlántico, Barranquilla, Casanare, Cundinamarca, La Guajira, Magdalena, Meta y Santa Marta y disminución en la entidad territorial de Vichada (Tabla 5).

Tabla 5. Entidades territoriales con comportamientos inusuales de mortalidad materna temprana respecto al promedio 2015-2019, Colombia semanas epidemiológicas 01 a 41 de 2020

\begin{tabular}{lccc} 
Entidad territorial de residencia & Valor observado & Valor histórico & Poisson \\
Atlántico & 15 & 10 & 0,035 \\
Barranquilla & 16 & 7 & 0,001 \\
Casanare & 4 & 1 & 0,015 \\
Cundinamarca & 24 & 12 & 0,001 \\
La Guajira & 31 & 19 & 0,003 \\
Magdalena & 16 & 9 & 0,011 \\
Meta & 9 & 5 & 0,036 \\
Putumayo & 5 & 2 & 0,036 \\
Santa Marta & 8 & 4 & 0,030 \\
Vichada & 1 & 5 & 0,034 \\
\multicolumn{5}{r}{ Fuente: Sivigila, Instituto Nacional de Salud, Colombia, 2015-2020 } \\
Nota: Las demás entidades territoriales no presentaron comportamientos inusuales.
\end{tabular}

En cuanto a las causas de muerte materna temprana el 41,8\% corresponde a causas directas y el 30,3\% a causas indirectas. Las principales causas de muerte son la hemorragia obstétrica con el $16,1 \%$ y el trastorno hipertensivo asociado al embarazo con el 14,9\% seguido por la neumonía por COVID 19 con el 12,4\% (Tabla 6).

\section{Tema central \\ Situación Nal. \\ Mortalidad \\ Trazadores \\ Brotes \\ COVID-19}

Tablas 
Tabla 6. Entidades territoriales con comportamientos inusuales de mortalidad materna temprana respecto al promedio 2015-2019, Colombia, semanas epidemiológicas 01 a 41 de 2020

\begin{tabular}{lrr} 
Razón /Causa agrupada & Casos & \\
DIRECTA & 135 & $\mathbf{4 1 , 8}$ \\
Hemorragia obstétrica & 52 & 16,1 \\
Trastorno hipertensivo asociado al embarazo & 48 & 14,9 \\
Sepsis relacionada con el embarazo & 23 & 7,1 \\
Otras causas directas & 4 & 1,2 \\
Embarazo terminado en aborto con causa directa: hemorragia & 3 & 0,9 \\
\hline Evento tromboembolico como causa básica & 3 & 0,9 \\
Embarazo terminado en aborto con causa directa: sepsis & 2 & 0,6 \\
INDIRECTA & 98 & $\mathbf{3 0 , 3}$ \\
Otras causas indirectas: Neumonía por COVID 19 & 40 & 12,4 \\
Sepsis no obstétrica & 19 & 5,9 \\
Otras causas indirectas & 18 & 5,6 \\
\hline Sepsis no obstétrica: Neumonia & 10 & 3,1 \\
Otras causas indirectas: Cancer & 6 & 1,9 \\
Evento tromboembolico como causa basica & 3 & 0,9 \\
Otras causas indirectas: Dengue & 2 & 0,6 \\
EN ESTUDIO Fuente: Sivigila, Instituto Nacional de Salud, Colombia, 2020 & 90 & $\mathbf{2 7 , 9}$ \\
& &
\end{tabular}

Para el análisis de los comportamientos inusuales, por ser la mortalidad materna un evento de baja frecuencia, se usa la distribución de probabilidades de Poisson por medio de la estimación de la probabilidad de ocurrencia del evento según su comportamiento medio entre el 2015 y 2019.

\section{Mortalidad perinatal y neonatal tardía}

A semana epidemiológica 41 de 2020, se han notificado 6883 casos de muerte perinatal y neonatal tardía (MPNT) de los cuales 128 corresponden a casos residentes en el exterior por lo que no se incluyen en el análisis. En esta semana se notificaron 157 casos, de los cuales 106 corresponden a esta semana y 51 a notificaciones tardías.

Hasta la semana epidemiológica analizada la razón preliminar nacional de mortalidad perinatal y neonatal tardía es de 14,2 muertes por cada 1000 nacidos vivos, en la tabla 7 se observa que en 21 entidades territoriales la razón es superior a la del país. Las 5 entidades territoriales con las razones más altas son Chocó $(33,7)$, Vichada $(29,8)$, Vaupés (28,7), San Andrés y Providencia $(26,5)$ y Córdoba $(20,2)$.
Tabla 7. Número de casos y razón de mortalidad perinatal y neonatal tardía por entidad territorial de residencia, Colombia, semanas epidemiológicas 01 a 41 de 2020

\begin{tabular}{|c|c|c|}
\hline $\begin{array}{l}\text { Entidad territorial de } \\
\text { residencia }\end{array}$ & $\begin{array}{l}\text { Número de } \\
\text { casos }\end{array}$ & $\begin{array}{l}\text { Razón de Mortalidad perinatal y neonatal } \\
\text { tardía por } 1000 \text { nacidos vivos }\end{array}$ \\
\hline Chocó & 137 & 33,7 \\
\hline Vichada & 33 & 29,8 \\
\hline Vaupés & 13 & 28,7 \\
\hline San Andrés y Providencia & 15 & 26,5 \\
\hline Córdoba & 368 & 20,2 \\
\hline Casanare & 81 & 18,6 \\
\hline La Guajira & 297 & 18,5 \\
\hline Barranquilla & 303 & 17,7 \\
\hline Guainía & 12 & 17,7 \\
\hline Cauca & 229 & 17,7 \\
\hline Nariño & 206 & 16,6 \\
\hline Quindío & 63 & 15,7 \\
\hline Cartagena & 207 & 15,4 \\
\hline Magdalena & 156 & 15,0 \\
\hline Buenaventura & 53 & 15,0 \\
\hline Putumayo & 49 & 14,9 \\
\hline Arauca & 50 & 14,8 \\
\hline Atlántico & 206 & 14,5 \\
\hline Bolívar & 174 & 14,4 \\
\hline Cali & 258 & 14,3 \\
\hline Cundinamarca & 373 & 14,2 \\
\hline Colombia & 6755 & 14,2 \\
\hline Tolima & 164 & 13,8 \\
\hline Bogotá & 880 & 13,8 \\
\hline Antioquia & 750 & 13,7 \\
\hline Risaralda & 100 & 13,5 \\
\hline Norte de Santander & 228 & 13,3 \\
\hline Caldas & 81 & 13,2 \\
\hline Cesar & 215 & 12,8 \\
\hline Boyacá & 127 & 12,7 \\
\hline Amazonas & 11 & 12,7 \\
\hline Sucre & 137 & 12,5 \\
\hline Meta & 130 & 12,0 \\
\hline Valle del Cauca & 164 & 11,6 \\
\hline Huila & 141 & 11,0 \\
\hline Santander & 217 & 10,6 \\
\hline Caquetá & 52 & 10,0 \\
\hline Santa Marta & 68 & 8,9 \\
\hline Guaviare & 7 & 7,4 \\
\hline
\end{tabular}

Fuente: Sivigila, Instituto Nacional de Salud, Colombia, 2020 (Datos preliminares). DANE, Estadísticas Vitales, Cifras preliminares nacimientos a septiembre 2019

\begin{tabular}{l} 
Tema central \\
Situación Nal. \\
Mortalidad \\
\hline Trazadores \\
\hline Brotes \\
COVID-19 \\
Tablas
\end{tabular}


Según el momento de ocurrencia de la muerte, la mayor proporción son muertes perinatales anteparto con 47,9\% (3233), seguido de neonatales tempranas con $27,5 \%$ (1 860), neonatales tardías con $13,7 \%$ (928), perinatales intraparto con 10,9\% (733) y sin dato para esta característica el 0,02\% (1).

De acuerdo con las causas de muerte agrupadas, se observó la mayor proporción en: otras causas de muerte 26,7 \% principalmente trastornos de origen perinatal y placentarios seguido por prematuridad-inmaturidad $22,7 \%$ y asfixia y causas relacionadas $20,7 \%$ (Figura 8 ).

Figura 8. Proporción de causas de muertes perinatales y neonatales tardías por causas de muerte agrupadas, Colombia, semanas epidemiológicas 01 a 41 de 2020

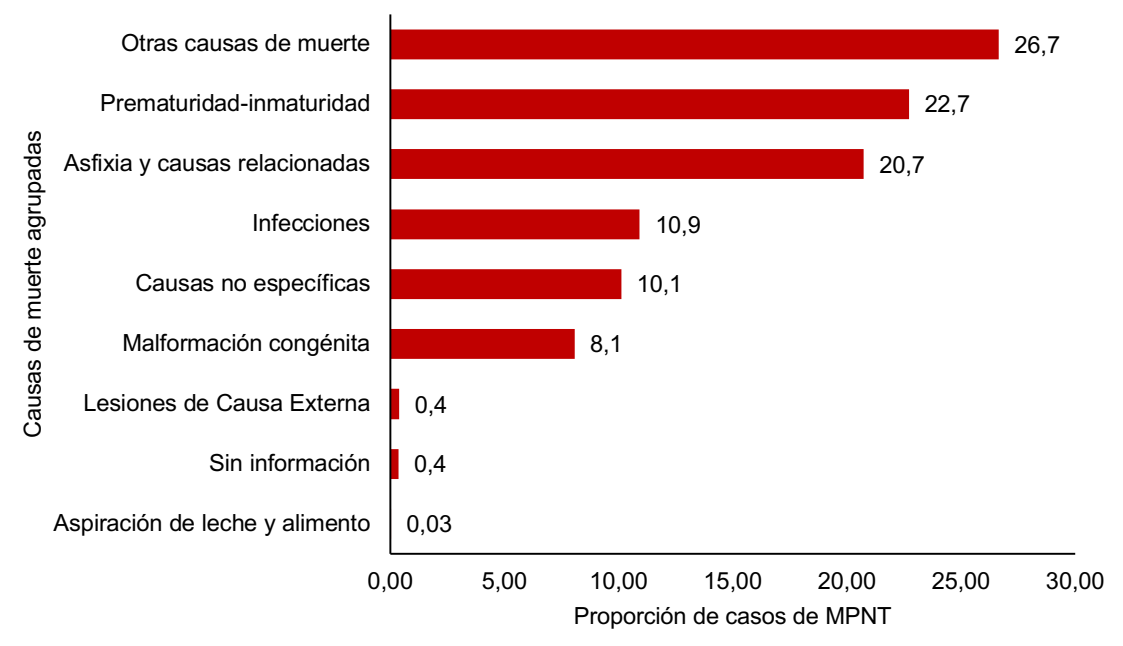

Fuente: Sivigila, Instituto Nacional de Salud, Colombia, 2020 (Datos preliminares).
En lo observado en la semana de análisis, en comparación con lo notificado entre 2015 y 2019, se presenta un incremento en la notificación en Casanare. Este comportamiento podría estar explicado por las acciones de búsqueda activa institucional que realiza el equipo de vigilancia territorial. Por otra parte, se presenta un decremento en la notificación en Antioquia, Atlántico, Bogotá, Caquetá, Cartagena, Risaralda y Sucre. Comportamiento que podría ser explicado por el subregistro en la notificación de las muertes a Sivigila, respecto al número de muertes certificadas en el Registro Único de Afiliados a la Protección Social-RUAF.

Dado que el evento tiene una alta frecuencia en notificación y se cuenta con una línea de base estable de más de cinco años, se realiza el análisis de los comportamientos inusuales a través del método: Morbidity and Mortality Weekly Report (MMWR) del Center for Disease Control and Prevention (CDC). Este se basa en la comparación del comportamiento actual del evento en el último periodo epidemiológico (valor observado) con el resultado del promedio de 15 periodos históricos alrededor de ese periodo de evaluación, la ventana histórica de estimación contempla los cinco años previos al año de análisis (Coutin G, Borges J, Batista R, Feal P, Suárez B. Método para el análisis del comportamiento observado de enfermedades seleccionadas con relación al comportamiento histórico. Rev Cubana Hig Epidemiol. 2000;38(3):157-66). 


\section{EVENTOS TRAZADORES}

\section{Infección respiratoria aguda}

\section{Vigilancia de morbilidad por infección respiratoria aguda}

A nivel nacional se identifica disminución en la notificación para la morbilidad por infección respiratoria aguda (IRA) en los servicios de consulta externa y urgencias y en las hospitalizaciones en sala general; se presenta incremento en las hospitalizaciones por IRA en unidad de cuidados intensivos e intermedios (tabla 8).

Tabla 8. Notificación morbilidad por Infección Respiratoria Aguda por tipo de servicio en Colombia, semana epidemiológica 41, 2019 y 2020

\begin{tabular}{lrrrr} 
Tipo de servicio & 2019 a semana 40 & 2020 a semana 40 & \multicolumn{2}{c}{ Variación } \\
Consultas externas y urgencias & 5322769 & 3431974 & 35,5 & Disminución \\
Hospitalizaciones en sala general & 181588 & 152318 & 16,1 & Disminución \\
Hospitalizaciones en UCl & 16959 & 33996 & 100,5 & Aumento \\
\multicolumn{1}{c}{ Fuente: Sivigila, Instituto Nacional de Salud, Colombia, 2019 a 2020 } & &
\end{tabular}

A semana epidemiológica 41 de 2020, en Colombia se han notificado 3431974 consultas externas y urgencias por IRA, presentando disminución frente a lo notificado a la misma semana de los tres años anteriores con el 35,5\% comparado con 2019, 38,8 \% frente a 2018 y $39,4 \%$ frente a 2017 . Teniendo en cuenta el comportamiento de notificación de los últimos seis años, se presenta disminución en 32 entidades territoriales; sólo Córdoba y Guainía presentan incremento; La Guajira, Norte de Santander, Santa Marta y Tolima no presentan comportamientos inusuales.

Por grupos de edad, los adultos de 20 a 39 años representan el $30,4 \%$ (1043 333), seguido por el de 40 a 59 años con el 20,4\% (701 620). La mayor proporción de consultas externas y de urgencias por IRA sobre el total de consultas por todas las causas se presenta en los niños de 1 año con el 11,3\%, seguido por los menores de 1 año con el 10,3\%.
En el canal endémico, las consultas externas y urgencias por IRA superaron el límite superior histórico esperado en 11 semanas epidemiológicas; a partir de la semana 13 a la 41 se ubican por debajo del umbral estacional y del límite inferior (figura 9).

Figura 9. Canal endémico de consultas externas y urgencias por infección respiratoria aguda, Colombia, semanas epidemiológicas 01 a 41, entre 2013 y 2020

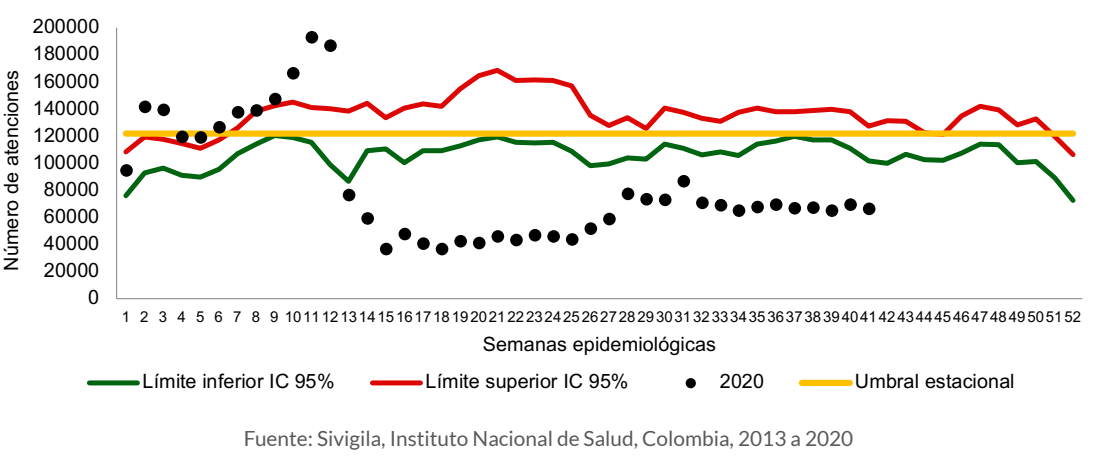

Se notificaron 152318 hospitalizaciones por IRAG en sala general, presentando disminución frente a lo notificado a la misma semana de los tres años anteriores con el 16,1 \% frente a 2019, 23,2 \% comparado con 2018 y $24,1 \%$ frente a 2017. Se presenta disminución en Barranquilla, Bolívar, Caldas, Cali, Chocó, Córdoba, Guainía, La Guajira, Magdalena, Putumayo, Quindío, San Andrés, Santa Marta, Sucre y Vaupés e incremento en Amazonas, Buenaventura, Cartagena, Huila, Meta, Santander, Tolima, Valle del Cauca y Vichada; no presentan comportamientos inusuales 14 entidades territoriales.

Por grupos de edad, los adultos de más de 60 años representan el 33,1 \% (50 459), seguido por los de 40 a 59 años con el 19,5 \% (29 694). La mayor proporción de hospitalizaciones en sala general por IRAG sobre el total de hospitalizaciones por todas las causas se presenta en los niños de 1 año con el $11,5 \%$, seguido por los menores de 2 a 4 años con el 9,5 \%.

En el canal endémico, las hospitalizaciones por IRAG en sala general se ubican entre los límites históricos esperados en 18 semanas epidemiológicas; se presenta un descenso en la notificación a partir de la semana 13 hasta la 26

\section{Tema central \\ Situación Nal. \\ Mortalidad \\ Trazadores \\ Brotes}

COVID-19

Tablas 
ubicándose por debajo del umbral estacional y del límite inferior; se superó el límite superior entre las semanas 30 y 35 (figura 10).

Figura 10. Canal endémico de hospitalizaciones por infección respiratoria aguda grave en sala general, Colombia, semanas epidemiológicas 01 a 41, entre 2013 y 2020

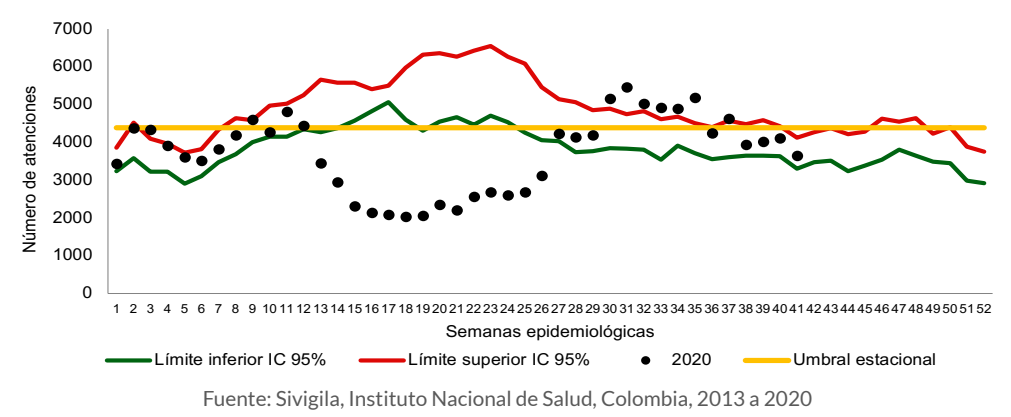

Se notificaron 33996 hospitalizaciones por IRAG en unidad de cuidados intensivos - $\mathrm{UCl}$ e intermedios, presentando incremento frente a lo notificado a la misma semana de los tres años anteriores con el 100,5 \% frente a 2019, 87,9 \% comparado con 2018 y 104,9 \% frente a 2017. Se presenta incremento en 27 entidades territoriales, entre las cuales resaltan Valle del Cauca, Caquetá, Nariño, Cundinamarca, Antioquia, Risaralda y Huila; las entidades que presentan disminución son Arauca y Córdoba.

Por grupos de edad, los adultos de más de 60 años representan el 48,8\% (16580), seguido por los de 40 a 59 años con el $24,2 \%$ (8226) y los menores de 1 año con el 11,1 \% (3 777). La mayor proporción de hospitalizaciones por IRAG en UCl sobre el total de hospitalizaciones en $\mathrm{UCl}$ e intermedio por todas las causas se presenta en el grupo de 40 a 59 años con el 20,1\%, seguido por el grupo de mayores de 60 años con el 19,6\%.

En el canal endémico, las hospitalizaciones por IRAG en UCl e intermedio superaron el umbral estacional y el límite superior histórico esperado en 33 semanas epidemiológicas; entre las semanas 15 a 17 y 19 a 21 se ubicaron entre los límites esperados; se presenta incremento progresivo a partir de la semana 22, alcanzando la mayor notificación en la semana 32, con disminución en las últimas 9 semanas (figura 11).
Figura 11. Canal endémico de hospitalizaciones por infección respiratoria aguda grave en unidades de cuidados intensivos, Colombia, semanas epidemiológicas 01 a 41, entre 2013 y 2020

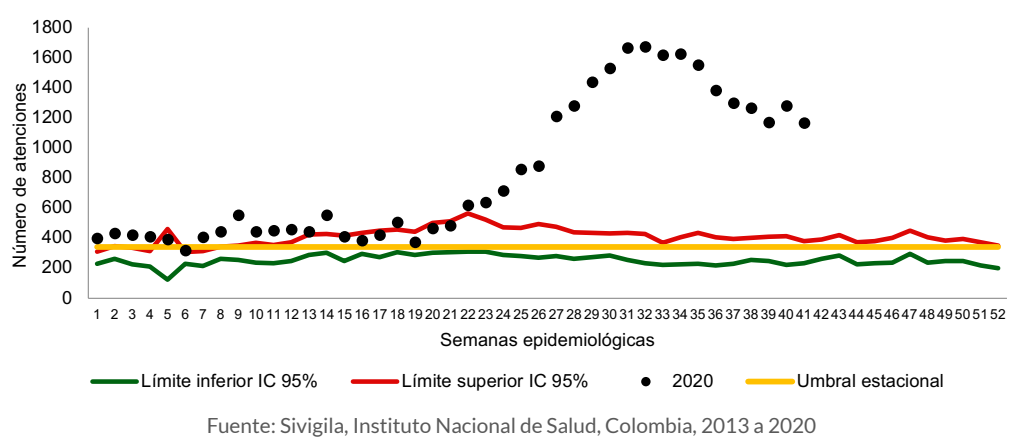

\section{Metodología:}

Vigilancia de morbilidad por IRA: los canales endémicos se realizaron con la metodología de Bortman con los datos de la morbilidad por infección respiratoria aguda mediante el cálculo de la media geométrica de los años 2014 a 2019 y su intervalo de confianza.

\section{Dengue}

En la semana epidemiológica 41 de 2020 se notificaron 731 casos probables de dengue: 310 de esta semana y 421 de otras semanas. En el sistema hay 71308 casos, 35007 (49,1\%), sin signos de alarma, 35 $519(49,8 \%)$ con signos de alarma y $782(1,1 \%)$ de dengue grave.

Los casos de dengue proceden de 32 departamentos, 5 distritos, 811 municipios y 12 países. Las entidades territoriales de Valle del Cauca, Cali, Huila, Tolima, Santander, Cundinamarca, Meta, Cesar, Antioquia, Caquetá, Córdoba y Sucre aportan el 80,9 \% (57 705) de los casos a nivel nacional (tabla 9).
Tema central

Situación Nal.

Mortalidad

Trazadores

Brotes

COVID-19

Tablas 
Tabla 9. Casos notificados de dengue por entidad territorial de procedencia y clasificación en Colombia, semanas epidemiológicas 01 a 41 de 2020

\begin{tabular}{|c|c|c|c|c|c|c|}
\hline & & & 116 & 14,8 & 14353 & 20,1 \\
\hline Cali & 11700 & 16,6 & 127 & 16,2 & 11827 & 16,6 \\
\hline Huila & 6580 & 9,3 & 114 & 14,6 & 6694 & 9,4 \\
\hline Tolima & 6292 & 8,9 & 41 & 5,2 & 6333 & 8,9 \\
\hline Santander & 3571 & 5,1 & 20 & 2,6 & 3591 & 5,0 \\
\hline Cundinamarca & 3339 & 4,7 & 17 & 2,2 & 3356 & 4,7 \\
\hline Meta & 2546 & 3,6 & 17 & 2,2 & 2563 & 3,6 \\
\hline Cesar & 2054 & 2,9 & 20 & 2,6 & 2074 & 2,9 \\
\hline Antioquia & 2014 & 2,9 & 29 & 3,7 & 2043 & 2,9 \\
\hline Caquetá & 1823 & 2,6 & 39 & 5,0 & 1862 & 2,6 \\
\hline Córdoba & 1520 & 2,2 & 11 & 1,4 & 1531 & 2,1 \\
\hline Sucre & 1433 & 2,0 & 45 & 5,8 & 1478 & 2,1 \\
\hline Atlántico & 1191 & 1,7 & 18 & 2,3 & 1209 & 1,7 \\
\hline Cauca & 1155 & 1,6 & 23 & 2,9 & 1178 & 1,7 \\
\hline Norte de Santander & 1146 & 1,6 & 10 & 1,3 & 1156 & 1,6 \\
\hline Casanare & 1103 & 1,6 & 5 & 0,6 & 1108 & 1,6 \\
\hline Bolívar & 977 & 1,4 & 30 & 3,8 & 1007 & 1,4 \\
\hline Barranquilla & 982 & 1,4 & 15 & 1,9 & 997 & 1,4 \\
\hline Putumayo & 818 & 1,2 & 3 & 0,4 & 821 & 1,2 \\
\hline Chocó & 681 & 1,0 & 4 & 0,5 & 685 & 1,0 \\
\hline Boyacá & 614 & 0,9 & 1 & 0,1 & 615 & 0,9 \\
\hline Cartagena & 542 & 0,8 & 15 & 1,9 & 557 & 0,8 \\
\hline Caldas & 537 & 0,8 & 8 & 1,0 & 545 & 0,8 \\
\hline Quindío & 521 & 0,7 & 0 & 0,0 & 521 & 0,7 \\
\hline Risaralda & 513 & 0,7 & 2 & 0,3 & 515 & 0,7 \\
\hline Magdalena & 489 & 0,7 & 11 & 1,4 & 500 & 0,7 \\
\hline Nariño & 398 & 0,6 & 7 & 0,9 & 405 & 0,6 \\
\hline La Guajira & 387 & 0,5 & 6 & 0,8 & 393 & 0,6 \\
\hline Arauca & 308 & 0,4 & 2 & 0,3 & 310 & 0,4 \\
\hline Santa Marta & 202 & 0,3 & 19 & 2,4 & 221 & 0,3 \\
\hline Buenaventura & 172 & 0,2 & 3 & 0,4 & 175 & 0,2 \\
\hline Exterior & 166 & 0,2 & 0 & 0,0 & 166 & 0,2 \\
\hline Amazonas & 158 & 0,2 & 0 & 0,0 & 158 & 0,2 \\
\hline Guaviare & 139 & 0,2 & 2 & 0,3 & 141 & 0,2 \\
\hline Archipiélago de San Andrés & 64 & 0,1 & 1 & 0,1 & 65 & 0,1 \\
\hline Vaupés & 64 & 0,1 & 0 & 0,0 & 64 & 0,1 \\
\hline Vichada & 47 & 0,1 & 0 & 0,0 & 47 & 0,1 \\
\hline Guainía & 39 & 0,1 & 1 & 0,1 & 40 & 0,1 \\
\hline Desconocido & 4 & 0,0 & 0 & 0,0 & 4 & 0,0 \\
\hline Total & 70526 & 100 & 782 & 100 & 71308 & 100 \\
\hline
\end{tabular}

Fuente: Sivigila, Instituto Nacional de Salud, Colombia, 2020
El 60,6\% (43246) de los casos de dengue se reportó en 45 municipios, con mayor frecuencia en: Cali, con 16,6 \% (11 827); Palmira, con 5,9 \% (4 217); Ibagué, con el 3,7 \% (2 606); Tuluá, con el 2,4 \% (1 710); Pitalito, con el 1,9\% (1 328); Buga, con el 1,8 \% (1 295); Candelaria, con el 1,5\% (1 034); Villavicencio (1030), Neiva (1016), Barranquilla (997), Yumbo (996) y Cartago (977), con 1,4\% respectivamente.

La incidencia nacional de dengue es de 266,6 casos por cada 100000 habitantes en riesgo. Para los departamentos de Valle del Cauca, Huila, Cundinamarca, Tolima, Caquetá, Amazonas, Boyacá y Putumayo, se estiman tasas de incidencia superiores a 400 casos por 100000 habitantes (figura 12).

Figura 12. Incidencia de dengue por entidad territorial de procedencia en Colombia, semanas epidemiológicas 01 a 41 de 2020

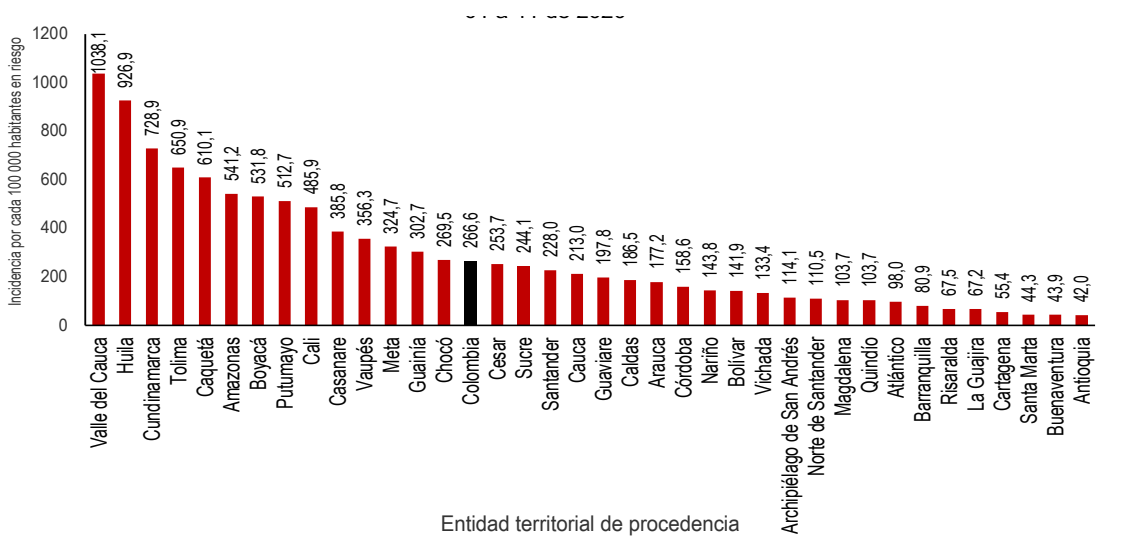

Fuente: Sivigila, Instituto Nacional de Salud, Colombia, 2020

Entre las semanas 01 a 11 el evento presentó un comportamiento por encima del número esperado de casos a nivel nacional comparado con su comportamiento histórico, sin embargo, a partir de la semana epidemiológica 12 de 2020 se observa un descenso marcado del evento ubicándose para esta semana dentro de lo esperado (figura 13). 
Figura 13. Canal endémico nacional de dengue en Colombia, semana epidemiológica 41, 2020

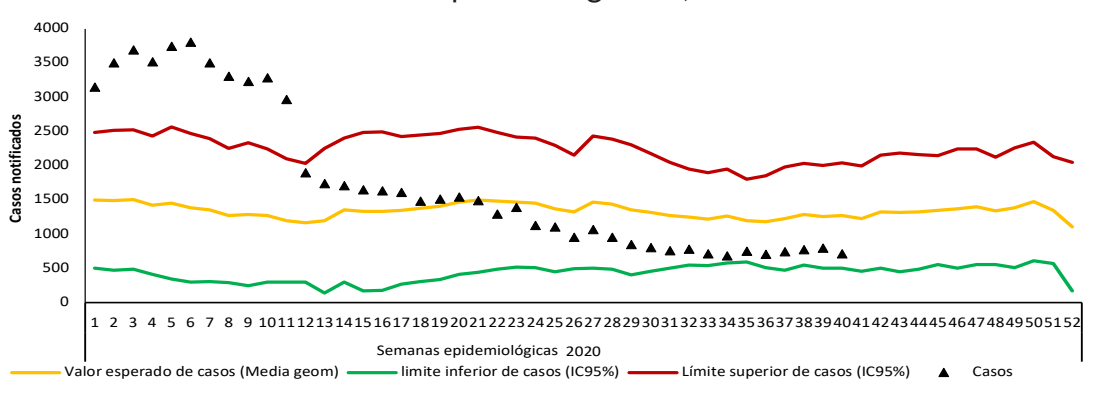

Fuente: Sivigila, Instituto Nacional de Salud, Colombia, 2020

De acuerdo con la situación epidemiológica según canal endémico, 1 entidad territorial presentó un comportamiento por debajo de lo esperado, 22 entidades se encuentran dentro de lo esperado, 9 entidades se encuentran en situación de alerta y 5 entidades con presentación de casos por encima del valor esperado, comparado con el comportamiento histórico (2013-2018) (tabla 10).

Tabla 10. Comparación de los casos notificados de dengue con su comportamiento histórico (2013 - 2018), por entidad territorial de procedencia en Colombia, semanas epidemiológicas 38 a 40 de 2020

\begin{tabular}{llll}
\hline $\begin{array}{l}\text { Comportamiento } \\
\text { epidemiológico }\end{array}$ & \multicolumn{3}{c}{ Entidad territorial } \\
\hline $\begin{array}{l}\text { Por debajo de lo } \\
\text { esperado }\end{array}$ & Antioquia & \\
\hline $\begin{array}{l}\text { Dentro del número } \\
\text { esperado de casos }\end{array}$ & Amazonas & Atlántico & Arauca \\
& Barranquilla & Buenaventura & Cesar \\
& Córdoba & Caquetá & Guaviare \\
& Putumayo & Guainía & Tolima \\
& La Guajira & Meta & Quindío \\
& Magdalena & Norte de Santander & Sucre \\
& Risaralda & Santa Marta & Santander \\
& Vaupés & Bolívar & Cali \\
& Boyacá & Cartagena & Cundinamarca \\
& Casanare & San Andrés, Providencia y Santa Catalina \\
\hline Situación de alerta & Huila & Caldas & Chocó \\
& Vichada & Valle del Cauca & \\
\hline Por encima del número Cauca & Nariño & & \\
esperado de casos & Fuente: Sivigila, Instituto Nacional de Salud, Colombia 2019
\end{tabular}

La información es notificada semanalmente por las entidades territoriales (ET) al Instituto Nacional de Salud (INS) a través del

Sistema de vigilancia en salud pública (Sivigila). El número de casos, puede variar después de que se realizan unidades de análisis en las ET para el ajuste y la clasificación de caso en cada evento.
Durante el 2020 se han notificado 145 muertes probables por dengue, de las cuales 43 han sido confirmadas procedentes de: Valle del Cauca, con 10 casos; Huila, con 5 casos, Santander y Tolima, con 4 casos cada uno; Cali y Cesar, con 3 casos cada uno; Atlántico y Cauca, con 2 casos cada uno; Bolívar, Caldas, Caquetá, Cartagena, Córdoba, Cundinamarca, Magdalena, Meta, Norte de Santander y Santa Marta, con 1 caso cada uno. Se han descartado 54 casos y se encuentran en estudio 48 muertes procedentes de: Valle del Cauca, con 10 casos; Cali, con 5 casos; Cundinamarca, con 4 casos; Cartagena, Córdoba y Sucre, con 3 casos cada uno; Atlántico, Barranquilla, Bolívar, Chocó y Santa Marta, con 2 casos cada uno; y Antioquia, Buenaventura, Caldas, Caquetá, Cauca, La Guajira, Guainía, Magdalena, Santander y Tolima, con 1 caso respectivamente.

\section{Metodología}

Se realizó un informe descriptivo de los casos notificados durante la semana epidemiológica 41 de 2020, teniendo en cuenta las variables de tiempo, persona y lugar contenidas en la ficha de datos básicos y complementarios. Los indicadores se presentan en distribuciones de frecuencias en figuras y tablas.

El canal endémico nacional y el análisis de comportamiento epidemiológico por entidad territorial se realizo con la metodología de medias geométricas (Marcelo Bortman), estableciendo los siguientes límites de control: por debajo de lo esperado, número de casos menor al límite inferior IC $95 \%$; dentro de lo esperado, número de casos entre el límite inferior y la media geométrica IC $95 \%$; en alerta, número de casos entre la media geométrica y el límite superior IC95\%, e incremento por encima de lo esperado, número de casos por encima del límite superior IC95\%.

En el canal endémico no se grafica la semana epidemiológica 41 de 2020 dado que, el periodo de incubación del virus de dengue es de 3 a 14 días, por lo tanto, los casos de esa semana se reflejarán plenamente en la siguiente semana.

\section{Malaria}

Según el análisis del último periodo epidemiológico, el país se encuentra en situación de alarma para malaria, con una tendencia a la disminución en las notificaciones de casos con respecto al mismo corte epidemiológico del 2019, como lo muestra el canal endémico (Figura 14). 
Figura 14. Canal endémico de malaria, Colombia, semana epidemiológica 41, 2020
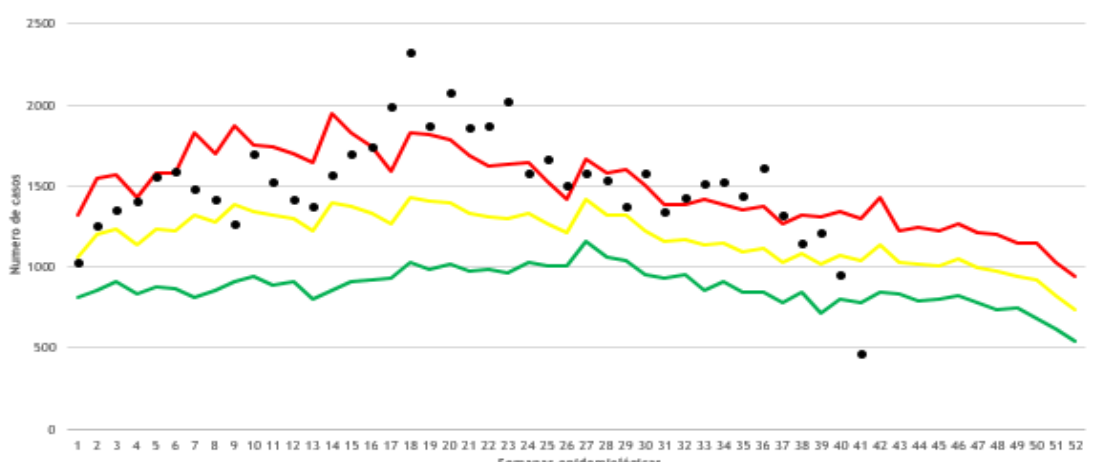

Promedito -

Fuente: Sivigila, Instituto Nacional de Salud, Colombia 2020

Nota: La información de brotes y alertas se analiza teniendo en cuenta las últimas cuatro semanas epidemiológicas.

En la semana epidemiológica 41 de 2020 se notificaron 1754 casos de malaria; a la fecha se tiene un acumulado de 62606 casos de malaria, de los cuales 61648 son de malaria no complicada y 958 de malaria complicada. Predomina la infección por Plasmodium falciparum (P.falciparum) con 49,7\% (31 144), seguido de Plasmodium vivax (P. vivax) con 49,4\% (30 930), e infección mixta con 0,8 \% (532).

\section{Malaria no complicada}

Por procedencia, Chocó (27,2 \%), Nariño (21,8\%), Antioquia $(9,4$ $\%)$, Córdoba (8,6\%) y Norte de Santander (6,9\%), aportan el 73,9\% de los casos de malaria no complicada.
Tabla 11. Casos notificados de malaria no complicada por entidad territorial de procedencia. Colombia, semanas epidemiológicas 01 a 41 de 2020

\begin{tabular}{|c|c|c|c|c|c|c|}
\hline Chocó & 238 & 9693 & 0 & 6824 & 16755 & 27,20 \\
\hline Nariño & 21 & 12307 & 0 & 1127 & 13455 & 21,80 \\
\hline Antioquia & 48 & 1080 & 0 & 4689 & 5817 & 9,40 \\
\hline Córdoba & 15 & 832 & 0 & 4446 & 5293 & 8,60 \\
\hline Norte de Santander & 2 & 3 & 0 & 4268 & 4273 & 6,90 \\
\hline Cauca & 2 & 3825 & 0 & 42 & 3869 & 6,30 \\
\hline Guainía & 24 & 409 & 0 & 2280 & 2713 & 4,40 \\
\hline Vichada & 7 & 654 & 0 & 1944 & 2605 & 4,20 \\
\hline Bolívar & 112 & 327 & 0 & 1088 & 1527 & 2,50 \\
\hline Guaviare & 2 & 467 & 0 & 973 & 1442 & 2,30 \\
\hline Amazonas & 7 & 74 & 0 & 1140 & 1221 & 2,00 \\
\hline Buenaventura & 3 & 753 & 0 & 44 & 800 & 1,30 \\
\hline Risaralda & 4 & 22 & 0 & 541 & 567 & 0,90 \\
\hline Meta & 6 & 234 & 0 & 318 & 558 & 0,90 \\
\hline Exterior & 13 & 44 & 0 & 235 & 292 & 0,47 \\
\hline Casanare & 2 & 4 & 0 & 81 & 87 & 0,10 \\
\hline Vaupés & 1 & 4 & 0 & 80 & 85 & 0,10 \\
\hline Cali & 0 & 30 & 0 & 13 & 43 & 0,10 \\
\hline Valle del Cauca & 3 & 15 & 0 & 19 & 37 & 0,10 \\
\hline Putumayo & 0 & 4 & 0 & 32 & 36 & 0,10 \\
\hline Arauca & 1 & 2 & 0 & 26 & 29 & 0,00 \\
\hline Sucre & 0 & 5 & 0 & 18 & 23 & 0,00 \\
\hline Cesar & 4 & 2 & 0 & 14 & 20 & 0,00 \\
\hline Caquetá & 0 & 3 & 0 & 14 & 17 & 0,00 \\
\hline Magdalena & 0 & 0 & 0 & 16 & 16 & 0,00 \\
\hline La Guajira & 0 & 3 & 0 & 9 & 12 & 0,00 \\
\hline Desconocido & 0 & 2 & 0 & 6 & 8 & 0,01 \\
\hline Santander & 0 & 1 & 0 & 7 & 8 & 0,00 \\
\hline Santa Marta & 0 & 3 & 0 & 5 & 8 & 0,00 \\
\hline Caldas & 0 & 1 & 0 & 5 & 6 & 0,00 \\
\hline Huila & 0 & 2 & 0 & 4 & 6 & 0,00 \\
\hline Barranquilla & 0 & 0 & 0 & 4 & 4 & 0,00 \\
\hline Quindío & 0 & 0 & 0 & 4 & 4 & 0,00 \\
\hline Cartagena & 0 & 1 & 0 & 2 & 3 & 0,00 \\
\hline Atlántico & 0 & 0 & 0 & 2 & 2 & 0,00 \\
\hline Boyacá & 0 & 0 & 0 & 1 & 1 & 0,00 \\
\hline Total & 515 & 30808 & 0 & 30325 & 61648 & 100 \\
\hline
\end{tabular}

Tema central

Situación Nal.

Mortalidad

Trazadores

Brotes

\section{COVID-19}

Tablas 


\section{Malaria Complicada}

Se notificaron 958 casos de malaria complicada, de los cuales 30 proceden del exterior y 928 proceden de 29 entidades territoriales.

De los casos de malaria complicada, 64,1\% (614) corresponde a hombres. El 42,3\% (405) se presenta en personas de 15 a 29 años, y 18,5\% (177) ocurrió en indígenas. Por lugar de procedencia, 52,9 \% (507) proviene de rural disperso. Por régimen de afiliación, 64,9 \% (622) pertenece al régimen subsidiado.

De los 958 casos notificados de malaria complicada, el 68,2 \% (653) presentó complicaciones hematológicas, el 16,5 \% (158) hepáticas y el 19,2\% (184) otras complicaciones (Figura 15).

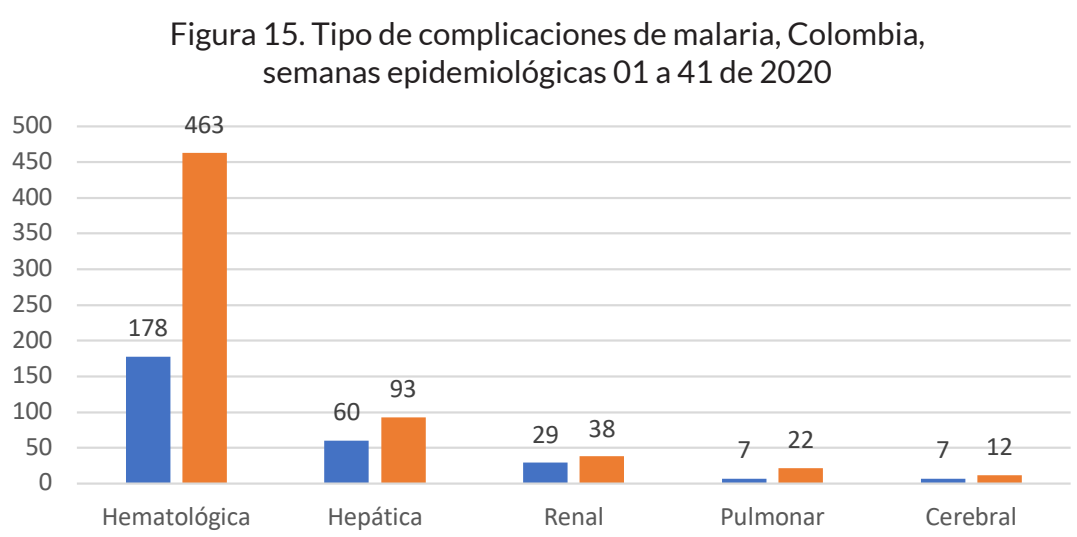

P. Falciparum P. Vivax

Fuente: Sivigila Instituto Nacional de Salud, Colombia, 2020 Nota: En la figura 16 no se incluyen los casos por malaria mixta

\section{Comportamientos inusuales}

A semana epidemiológica 41, 5 departamentos están por encima del número esperado de casos y 3 departamentos están en situación de alerta para malaria (Tabla 12).

Tabla 12. Distribución de entidades territoriales según el comportamiento epidemiológico de malaria, Colombia, semanas epidemiológicas 01 a 41 de 2020

\begin{tabular}{llll}
\hline & & & \\
\hline Menor al comportamiento histórico & Amazonas & & \\
En el comportamiento histórico & Guajira & Arauca & Atlántico \\
& Caquetá & Valle del Cauca & Buenaventura \\
& Huila & Vaupés & Magdalena \\
& Putumayo & Quindío & Santander \\
& Cesar & Sucre & Antioquia \\
& Caldas & Risaralda & Bolívar \\
& Guaviare & Choć & Cauca \\
Situación de alerta & Meta & Córdoba & Vichada \\
Mayor al comportamiento histórico & Vichada & Norte de Santander & Casanare \\
& Guainía & & Nariño \\
& Fuente: Sivigila, Instituto Nacional de Salud, Colombia 2020 & \\
Nota: La información de brotes yalertas se analiza teniendo en cuenta las últimas cuatro semanas epidemiológicas
\end{tabular}

A semana epidemiológica 41, 23 municipios se encuentran en situación de brote; los que más reportan casos son: Tibú (Norte de Santander), Tierralta (Córdoba), Puerto Inírida (Guainía), Cumaribo (Vichada), Timbiquí (Cauca), Roberto Payán (Nariño) y Alto Baudó (Chocó) (Tabla 13). 
Tabla 13. Municipios en situación de brote, a semana epidemiológica 41, 2020 Colombia

\begin{tabular}{lrrrr} 
Departamento & Municipio & $\begin{array}{r}N^{\circ} \text { de casos } \\
\text { acumulados } \\
\text { SE } 40\end{array}$ & Esperado & Observado \\
\cline { 2 - 5 } Norte de Santander & Tibú & 3737 & 114 & 160 \\
Córdoba & Tierralta & 3173 & 168 & 348 \\
Guainía & Puerto Inírida & 2657 & 117 & 341 \\
Vichada & Cumaribo & 2594 & 40 & 165 \\
Cauca & Timbiquí & 2438 & 76 & 57 \\
Nariño & Roberto Payán & 2329 & 84 & 220 \\
Chocó & Alto Baudó & 1905 & 107 & 242 \\
Nariño & Maguí & 1884 & 40 & 101 \\
Cauca & Guapi & 1218 & 47 & 95 \\
Córdoba & Puerto Libertador & 1196 & 56 & 109 \\
Nariño & Mosquera & 1155 & 39 & 166 \\
Chocó & Medio Baudó & 739 & 35 & 73 \\
Nariño & Lrancisco Pizarro & 507 & 11 & 32 \\
Nariño & La Tola & 503 & 7 & 36 \\
Antioquia & Murindó & 455 & 13 & 76 \\
Bolívar & Río Viejo & 434 & 19 & 48 \\
Norte de Santander & El Tarra & 429 & 9 & 29 \\
Chocó & Carmen Del Darién & 413 & 11 & 45 \\
Meta & Puerto Gaitán & 375 & 4 & 25 \\
Bolívar & Norosí & 303 & 12 & 21 \\
Antioquia & Nechi & 208 & 11 & 30 \\
Casanare & Hato Corozal & 78 & 0 & 31 \\
Norte de Santander & Teorama & 1 & 6 \\
Nota: La información de brotesy ylertas se analiza teniendo en cuenta lasúltimas cuatro semanas epidemiológicas
\end{tabular}

\section{Metodología}

Se realizó un análisis descriptivo con corte a semana epidemiológica 41 de 2020, con información que incluye: descripción de los casos en tiempo, lugar y persona, análisis de tendencia, comportamientos inusuales, descripción y análisis de indicadores para la vigilancia.

\section{BROTES Y SITUACIONES DE EMERGENCIA EN SALUD PÚBLICA}

\section{ALERTAS NACIONALES}

Brote por enfermedad transmitida por alimentos (ETA). Sativasur, Boyacá.

El 09 de octubre se presentó un brote de ETA en población minera del municipio de Sativasur, con una tasa de ataque del $50 \%(12 / 24)$; cuadro clínico consistente en vómito, diarrea y cefalea. El alimento probablemente implicado fue arroz con pollo preparado en el campamento; los afectados fueron atendidos en el Centro de Salud del municipio de Socha, con manejo ambulatorio sin complicaciones, situación en seguimiento

Fuente: Secretaria de Salud de Boyacá

\section{ALERTAS NACIONALES}

\section{Enfermedades por virus de Oropouche - Guayana Francesa, Francia. Fecha de publicación 13 de octubre de 2020}

La Agencia Regional de Salud de la Guayana Francesa (ARS) informo de la detección del virus Oropouche (VORO) en la Guayana Francesa. El 22 de septiembre de 2020, el instituto miembro del Laboratorio Nacional de Referencia Frances, Instituto Pasteur de Cayena notifico al punto focal Nacional del RSI de Francia siete casos confirmados por laboratorio de VORO en el pueblo de Saül. Identificados posterior a las investigaciones clínicas por un número inusualmente alto de enfermedades similares al Dengue.

Entre el 11 de agosto y el 25 de septiembre se identificaron en Saül 37 casos clínicamente compatibles de enfermedad por el virus Oro-

\begin{tabular}{l} 
Tema central \\
Situación Nal. \\
Mortalidad \\
\hline Trazadores \\
\hline Brotes \\
COVID-19 \\
\hline Tablas
\end{tabular}


pouche. Los resultados de la serología para dengue, Chikunguña y zika negativos. Entre los 37 casos clínicamente compatibles, el $60 \%$ con nombres con una mediana de edad de 36 años (rango de 3 a 82 años). El rango más representativo es el de 15 a 54 años. Se observo un pico de casos a mediados de septiembre, no obstante, la investigación del brote continua.

La población oficial del pueblo de Saül es de 150 personas y la única forma de entrar es a través del aeropuerto a 45 minutos debido a que está en medio de la selva amazónica. Sin embargo, por la disminución drástica de los vuelos la población bajo entre 50 a 80 personas. Por lo tanto, la tasa de ataque podría llegar al $70 \%$. Hasta el momento no se han informado más casos en Saül.

Las acciones realizadas en salud publica incluyen la misión de investigación entomológica que finalizo el 3 de octubre, mensajes de prevención dirigidos a la población local, turística y población que pasa por el pueblo. Esta es la primera detección del virus en esta zona, a la fecha no hay evidencia de transmisión directa del virus Oropouche de persona a persona. La Organización Mundial de la Salud (OMS) recomienda la vacunación de fiebre amarilla al menos 10 días antes del viaje a la Guayana francesa, las medidas de control de vectores se basan en la reducción de la población de mosquitos mediante la erradicación de los criaderos, medidas de protección personal basadas en la prevención de picaduras, con el uso de ropa tratada con repelente, mosquiteros.

Fuente: Organización Mundial de la Salud (OMS). Enfermedad por virus de Oropouche - Guayana Francesa, Francia Fecha de publicación 13 de octubre. Fecha de consulta 15 de octubre de 2020. Disponible en: https://www.who.int/csr/don/13-october-2020-oropouche-french-guiana-france/en/

Boletín semanal sobre brotes y otras emergencias. África, Semana Epidemiológica 41: del 5 al 11 de octubre de 2020. Enfermedad por el virus del ébola. Provincia de Équateur, República democrática del Congo. Fecha de publicación 11 de octubre de 2020.
El brote de la enfermedad por el virus del ébola (EVE) en la provincia de Équateur, ha presentado un leve decremento de casos y muertes. En los pasados 21 días (desde 20 de septiembre de 2020 al 10 de octubre) se ha confirmado un caso de EVE en 42 áreas de 13 zonas de salud. Bekungu área de salud en Monieka zona de salud no ha presentado casos reportados en los últimos 42 días.

Al 10 de octubre de 2020 se ha reportado un total de 128 casos (119 confirmados y nueve probables) incluidos 53 fallecidos (tasa de letalidad 41,4\%). El número de trabajadores de salud afectados se mantiene en tres, representa el 2,3\% de todos los casos. De los 169 contactos activos 136 (80,5\%) han recibido un seguimiento. De los 31 contactos que no han sido valorados, $18(58,1 \%)$ no se pudieron contactar, cuatro $(12,9 \%)$ se perdieron durante el seguimiento, y nueve restantes ( $25 \%$ ) no habían sido vistos en las últimas 24 horas. Un total de 813 nuevas alertas (Incluidas 20 muertes) fueron reportados en 12 zonas de salud. De las 813 aleras registradas a la fecha (incluidas 20 muertes) 829 (95,8\%) fueron investigadas y 80 $(36,4 \%)$ fueron validadas.

Acciones relacionadas con la respuesta: al 10 de octubre de 2020 los puestos de control (PDC) reportaron un total de 39591 viajeros pasaron por los PDC y 37358 (94,5\%) fueron revisados. De las 221 alertas detectadas se han validado 113 . Al 10 de octubre de 2020 se han recibido 204 muestras en cuatro laboratorios operativos desde el comienzo del brote con un total de 10269 muestras. Un total de 294 nuevas personas fueron vacunadas con rVSV-ZEBOV-GP al 10 de octubre de 2020, incluidos tres contactos de contactos, y 291 contactos probables. Desde el 5 de junio se han vacunado 36816 personas. Se han realizado actividades de comunicación del riesgo, movilización y participación comunitaria.

Fuente: Organización Mundial de la Salud (OMS). Boletín semanal de brotes y otras emergencias. África. Fecha de publicación 11 de octubre. Fecha de consulta 15 de octubre de 2020. Disponible en: https://apps.who.int/iris/bitstream/handle/10665/336026/ OEW41-0511102020.pdf 


\section{Reporte semanal de situación epidemiológica mundial de en-} fermedad por coronavirus (COVID -19). Fecha de publicación 13 de octubre de 2020. Organización Mundial de Salud (OMS).

En la última semana se han notificado 2,2 millones de casos nuevos y 39000 muertes por COVID-19, el mayor número de caso notificado por semana. Hasta el 11 de octubre se han registrado más de 37 millones de casos y 1 millón de muertes a nivel mundial. De estos el $48 \%$ de los casos y el $55 \%$ de las defunciones continúan en la región de las Américas. La región de Asia sudoriental informo una disminución de casos nuevos y muertes principalmente por la disminución de los casos notificados en inicia y Bangladesh mientras que las regiones del mediterráneo occidental y pacífico occidental presentaron un aumento de casos t muertes. En general, durante el período que abarca el informe, todas las Regiones mostraron un aumento de casos excepto Asia Sudoriental.

En la Región Africana, aunque se experimentaba una disminución lenta pero continua de casos desde julio, se notificó en la última semana un aumento del $11 \%$. Las cifras actuales representan el 1 $\%$ de los casos confirmados y el $3 \%$ de las muertes notificadas en todo el mundo en la última semana. También se reporta el aumento del número de países que han notificado casos. Suráfrica y Etiopia notificaron el mayor número de casos nuevos en la última semana, seguido de Kenia, Uganda y Argelia. Suráfrica presenta un aumento de número de muertes reportado la última semana representando el $74 \%$ de las muertes nuevas de la región.

La semana pasada, Mozambique registró 795 nuevos casos $(25$ por millón de habitantes), lo que eleva la cifra total a casi 10000 casos. Sin embargo, el país ha registrado un descenso gradual durante las últimas tres semanas. El número de pruebas por 1000 habitantes se ha mantenido en 0,3 durante las 10 semanas y la tasa de positividad ha caído en la última semana al $9 \%$.

La Región de las Américas notificó más de 800000 casos nuevos en los últimos siete días, lo que representa un aumento del $6 \%$ con respecto a la semana anterior. Los países que maz registraron casos nuevos y fallecidos fueron Estados Unidos de América, Brasil, Argentina, México y Colombia. Canadá ha registrado un aumento del número de casos desde septiembre en un $27,7 \%$ de casos y 14,3 de muertes. La mayoría de los casos se notificaron en Quebec y Ontario.

Desde mediados de julio, las tasas de incidencia entre los 20 y los 39 años se han mantenido consistentemente más altas con aumento creciente de los casos en este rango de edad en hospitalización. Costa Rica, con la segunda incidencia más alta de casos por millón de habitantes en la Región, ha alcanzado más de 86000 casos y más de 1000 muertes. El país ha reportado más de 107 hospitalizaciones por COVID-19 por millón de habitantes de los cuales más de un tercio se encuentran en unidades de cuidados intensivos.

En la región del Mediterráneo Oriental el número semanal de nuevos casos y muertes ha aumentado en un $10 \%$ y $13 \%$ respectivamente en comparación con la semana anterior. La República Islámica de Irán es la más afectada de la región, con un $20 \%$ de todos los casos esta semana. Omán presenta un aumento de más del $60 \%$ del número de casos nuevos en la última semana.

La gobernación y otra sala de aislamiento en el Hospital Sur en la región de Sharqiya del Sur se abrieron para ayudar mitigar el creciente número de casos de COVID-19 en el país. En Túnez, ha habido un pico de casos nuevos (más de 2500) y muertes (más de 40) también reportadas esta semana por lo que se hizo énfasis en el aislamiento y recortes de horas de trabajo del sector público, así como toques de queda para reducir la transmisión.

La Región Europea registró la mayor incidencia semanal de casos de COVID-19 desde el inicio de la pandemia con casi 700000 nuevos casos notificados. La incidencia semanal de casos y defunciones aumentó un 34 \% y 16 \% respectivamente en comparación con la semana anterior. Europa es la segunda más activa del mundo contribuyendo con casi un tercio de los casos nuevos semanales.

Reino Unido, Francia, la Federación de Rusia y España representan más de la mitad de todos los casos nuevos notificados en la región. Letonia, las Islas Feroe e Islandia han informado del mayor aumento porcentual de casos nuevos en la semana pasada. España, con más de 50 000 casos notificados la semana pasada, está mostrando un descenso notable en la incidencia de casos y muertes del $24 \%$ y $19 \%$ respectivamente. En la última semana, se realizaron más de 740000 pruebas diagnósticas (PCR) (16 pruebas por 1000 habitantes por semana). La incidencia de casos y muertes en Polonia aumentó esta semana en un 
$93 \%$ y $104 \%$ respectivamente en comparación con la semana anterior, con casi 23500 nuevos casos y 370 muertes notificadas.

La Región del Pacífico Occidental representa el menor número de casos reportados a nivel mundial esta semana, sin embargo, se ha observado un aumento del $6 \%$ en los casos notificados recientemente y un aumento del $26 \%$ en las muertes notificadas en los últimos siete días. Los nuevos casos en Filipinas se han estabilizado durante las últimas 3 semanas con alrededor de 18000 casos notificados semanalmente, inferior al pico de 30000 casos reportados a mediados de agosto, sin embargo, continúan representando el mayor número de casos nuevos en la región debido a la flexibilización de las restricciones de cierre y la reapertura del sistema económico. Davao contribuyó con el 65 \% del total de casos de la región en las últimas dos semanas. En la Polinesia Francesa, hubo un pico de casos nuevos esta semana, lo que representó en un aumento del $62 \%$ con respecto a la semana pasada. Con la mayoría de los casos detectados en la Isla de Tahití. La tasa de positividad de las pruebas COVID-19 es actualmente es alto (26,3\%), sin embargo, solo se están evaluando personas sintomáticas.

La OMS ha elaborado una guía sobre la evaluación de riesgos y la gestión de la exposición de trabajadores, infección, prevención y control durante la atención medica cuando se sospecha o se confirma la enfermedad por coronavirus (COVID-19) y Asesoramiento sobre el uso de mascarillas en el contexto de COVID-19, uso racional de elementos de protección personal para COVID-19 y sus consideraciones durante la situación de escases severa. También ha desarrollado un protocolo de vigilancia dirigido a trabajadores de la salud que dan positivo para COVID-19.

Fuente: Organización Mundial de la Salud (OMS). Reporte de situación semanal de enfermedad por Coronavirus (COVID-19). Fecha de publicación 13 de octubre de 2020. Fecha de consulta 15 de octubre de 2020. Disponible en: https://www.who.int/docs/ default-source/coronaviruse/situation-reports/20201012-weekly-epi-update-9.pdf

\section{Situación COVID-19 Colombia}

Con corte a 15 de octubre de 2020, se confirmaron por laboratorio 936 982 casos de COVID-19 en Colombia en 38 entidades territoriales del orden departamental y distrital, afectando 1074 municipios. La incidencia acumulada es de 1834,53 casos por cada 100000 habitantes. Se encuentran activos 79585 casos, el 70 \% (71 949) se reportan en 18 municipios y 4 distritos: Bogotá, Medellín, Cali, Neiva, Bucaramanga, Valledupar, Bello, Manizales, Ibagué, Armenia, Popayán, Pereira, Villavicencio, Barrancabermeja, Tunja, Envigado, Itagüí, Pasto, Cúcuta, Floridablanca, Florencia, y Barranquilla.

La mayor incidencia de casos activos por 100000 habitantes (población DANE urbana y rural), se presenta en los municipios de: Archipiélago de San Andrés, Archipiélago de San Andrés - San Andrés $(208,9,7)$, Huila - Neiva $(1053,2)$, Puerto Gaitán - Meta $(966,7)$, Boyacá - Puerto Boyacá $(762,6)$, Boyacá - Tunja $(736,3$, Caquetá - Florencia $(720,52)$, Vaupés - Carurú $(720,33)$.

La edad promedio de los casos activos es 41,4 años \pm 19 , el $54 \%$ (43 101) se presenta en personas entre 15 a 44 años. De acuerdo con la ubicación de los casos, el 78,4 \% (62 444) de los casos activos se encuentra en casa y el 19,5\% (15 239) hospitalizados. 
Mapa 1. Incidencia de casos COVID-19 por entidad territorial, Colombia, semana epidemiológica 38 - 41, 2020

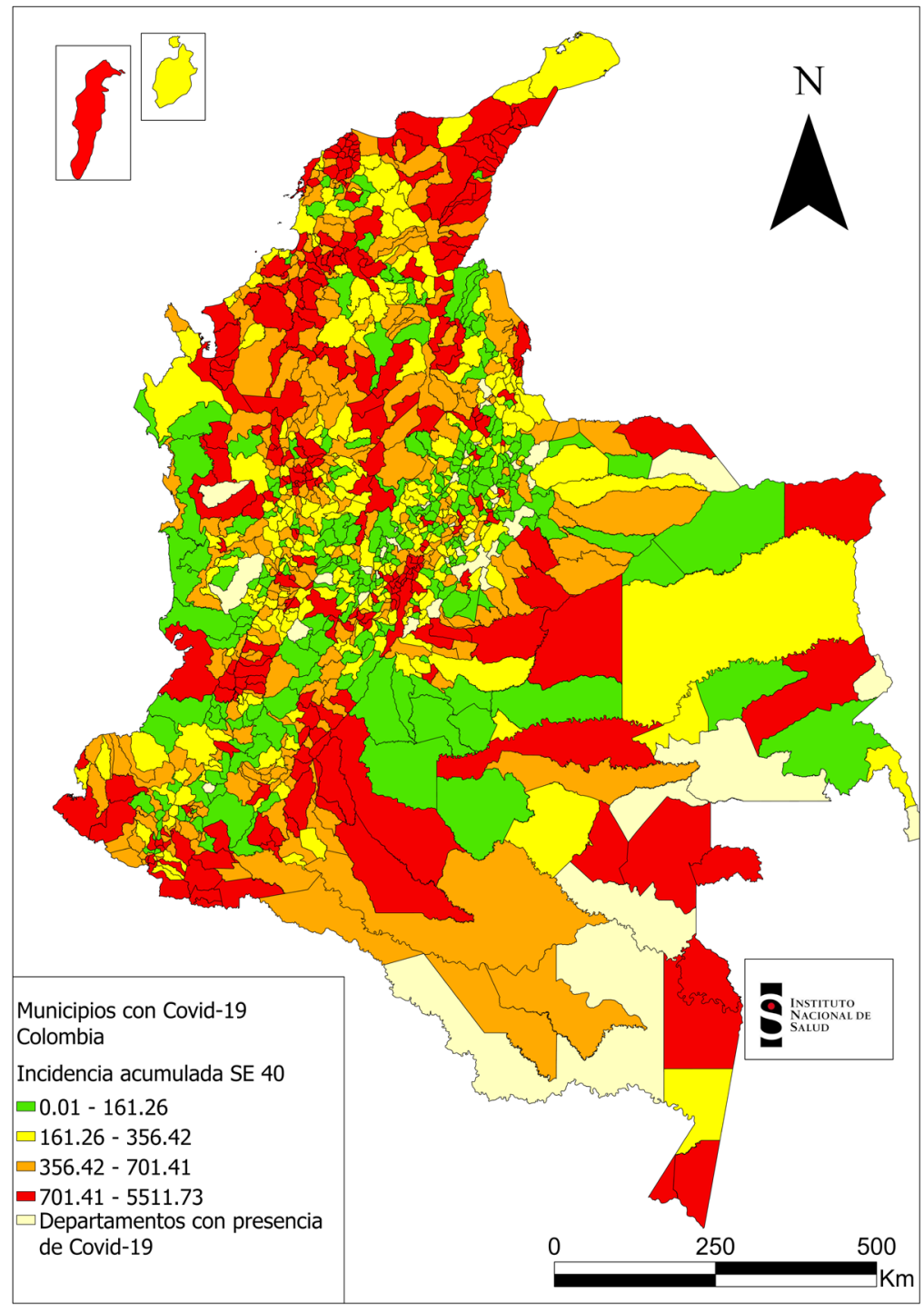

Entre el 13 de septiembre al 10 de octubre, se reportaron 140879 casos de COVID-19, para una incidencia de 284,09 casos por 100000 habitantes. Las entidades territoriales que durante este periodo superan la incidencia de periodo nacional son San Andrés, Providencia y Santa Catalina $(1073,9)$, Bogotá $(527,0)$, Huila $(495,7)$, Quindío $(353,3)$, Guaviare $(520,4)$, Caquetá $(390,2)$, Antioquia $(386,1)$, Guainía $(379,2)$, Cali $(356,6)$, Risaralda $(351,9)$, Meta $(334,8)$, Cesar $(330,0)$, Vaupés $(328,8)$, Casanare $(301,5)$, Santander $(298,3)$, Caldas $(297,5)$. El 10,5\% (4) de las entidades territoriales presentan un aumento de la incidencia con respecto al periodo anterior: Quindío $(\Delta 33,6)$, Casanare $(\Delta 25,3)$, Caldas $(\Delta 7,2)$ y Boyacá $(\Delta 6,7)$.

Durante este periodo, el 90,7 \% (927) de los municipios con confirmación de COVID-19 tienen casos activos, el 33,8 \% (314) de los municipios con casos activos presentan un incremento significativo de la incidencia con respecto al periodo anterior, observándose las mayores variaciones: Huila - Neiva $(\Delta 1053,2)$, Boyacá - Puerto Boyacá $(\Delta 762,6)$, Boyacá - Tunja $(\Delta 736,33)$, Vaupés - Carurú $(\Delta 720,33)$, Quindío - Armenia $(\Delta$ $638,4)$, Antioquia - Envigado $(\Delta 598,11)$, La Guajira - Urumita $(\Delta 581,3)$, Antioquia - Don Matías $(\Delta 572,9)$, Cundinamarca - Nemocón $(\Delta 560,4)$.

Se han reportado hasta este corte 28457 muertes, notificadas en 37 entidades territoriales (departamentos y distritos). El $25,3 \%$ de las muertes se registraron en Bogotá, $(9,7 \%)$, Antioquia, $(8,8 \%)$ en Valle $(8,8 \%)$, Barranquilla (5,9\%), Cordoba (5,6 \%), Santander (5,3\%), Atlántico (4,9 $\%)$, y Cundinamarca $(3,9 \%)$.

Entre el 13 de septiembre al 10 de octubre, la tasa de mortalidad por 100 000 habitantes (población DANE urbana y rural), es 8,87 y se concentra en los siguientes municipios de: Caquetá - Morelia $(53,4)$, Cundinamarca - Nemocón $(48,2)$, Santander - San Joaquín $(45,5)$, Huila - Tello $(42,5)$, Boyacá - San Jose de Pare $(40,1)$, Caldas - Anserma $(38,3)$, La Guajira - El Molino $(38,1)$, Huila - Neiva $(37,4)$, Santander - Barrancabermeja $(34,3)$, Cesar - La Gloria $(32,6)$, Arauca - Saravena $(30,2)$.

Fuente: INS- Sala de Análisis del Riesgo COVID19, 2020 
Mapa 2. Mortalidad por COVID-19 por entidad territorial, Colombia, semana epidemiológica 38 - 41, 2020

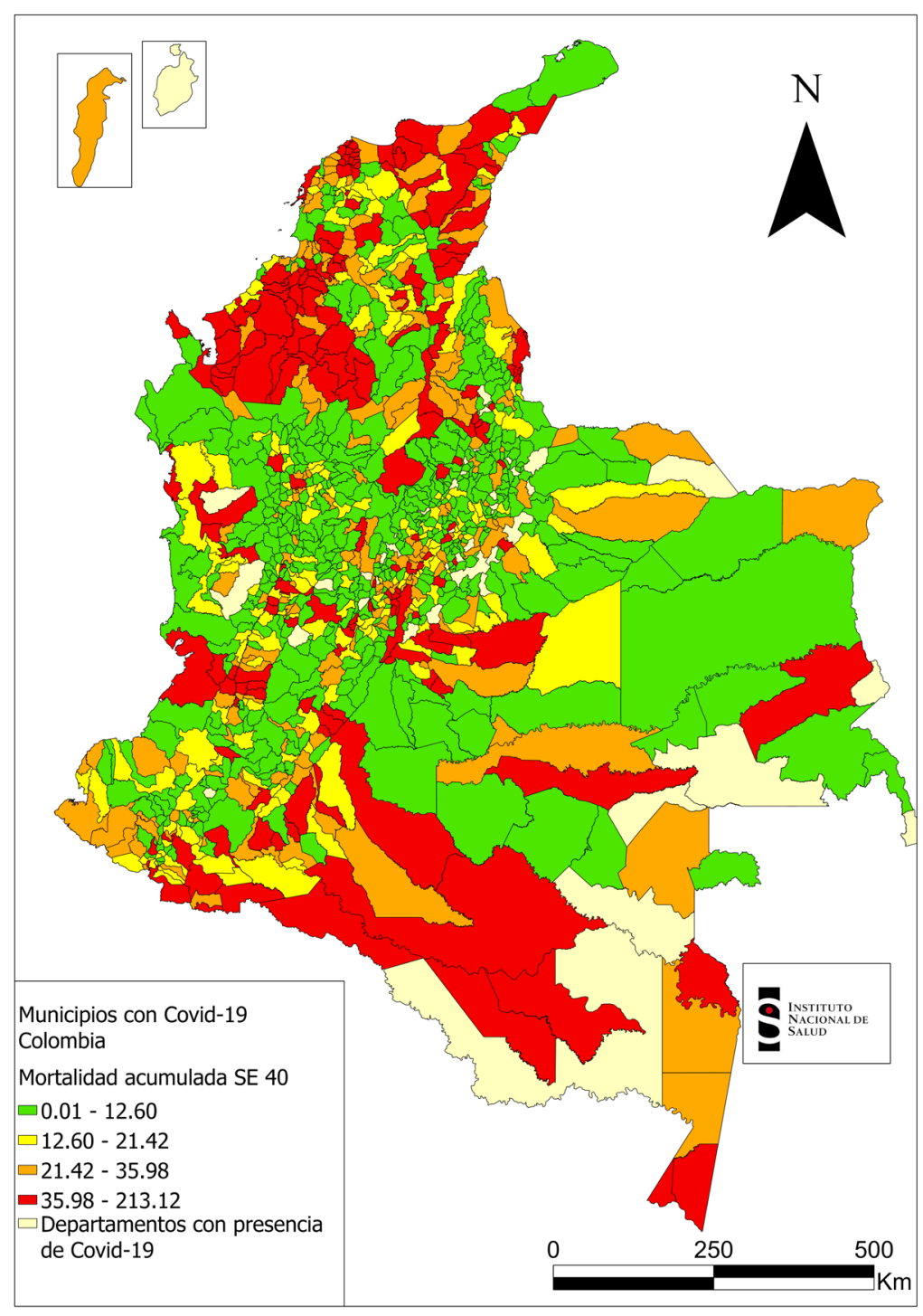

Fuente: INS- Sala de Análisis del Riesgo COVID19, 2020
Al comparar el indicador de letalidad observado durante las semanas epidemiológicas 38 a 41 con el periodo anterior, el 9,2 \% (104) de los municipios que han registrado casos fatales tuvieron un aumento significativo y 53 municipios tienen una letalidad mayor al percentil 75 $(14,3 \%) .8$ municipios en 7 departamentos (Antioquia - Liborina, Caquetá - San Vicente del Caguán, Cesar - La Gloria, Cesar - San Alberto, Cundinamarca - Nemocón, Huila - Tello, Norte de Santander - Tibú y Vaupés - Mitú) tuvieron un aumento significativo en la tasa de letalidad y en la tasa de mortalidad en el grupo de mayor de 60 años y en el grupo de 14 a 44 años.

Tema central
Situación Nal.
Mortalidad
Trazadores
Brotes
COVID-19
Tablas




\section{TABLAS DE MANDO NACIONAL}

\begin{tabular}{|c|c|c|c|c|c|c|c|c|c|c|c|c|c|c|c|c|c|c|}
\hline \multirow[b]{2}{*}{ Departamento } & \multicolumn{3}{|c|}{ Accidente ofídico } & \multicolumn{3}{|c|}{$\begin{array}{c}\text { Agresiones por animales } \\
\text { potencialmente transmisores de } \\
\text { rabia } \\
\end{array}$} & \multicolumn{3}{|c|}{ Dengue } & \multicolumn{3}{|c|}{ ESAVI grave } & \multicolumn{3}{|c|}{ Hepatitis A } & \multicolumn{3}{|c|}{ Intento de suicidio } \\
\hline & 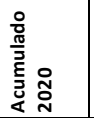 & $\begin{array}{l}\frac{0}{0} \\
\frac{0}{0} \\
\frac{0}{4}\end{array}$ & 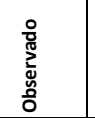 & 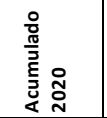 & 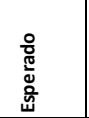 & 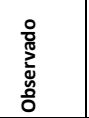 & 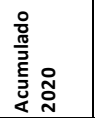 & $\begin{array}{l}\frac{0}{0} \\
\text { 产 } \\
\text { 递 } \\
\end{array}$ & 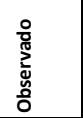 & 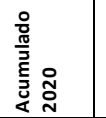 & $\begin{array}{ll}\frac{0}{0} \\
\frac{0}{0} \\
\frac{0}{4} \\
\end{array}$ & 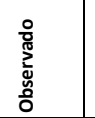 & 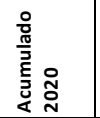 & 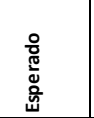 & 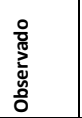 & 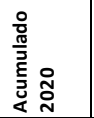 & $\begin{array}{ll}\frac{0}{0} \\
\frac{0}{0} \\
\frac{0}{0} \\
\end{array}$ & 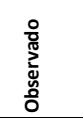 \\
\hline Amazonas & 33 & 1 & 1 & 201 & 5 & 5 & 158 & 16 & 6 & 0 & 1 & 0 & 1 & 0 & 0 & 42 & 46 & 42 \\
\hline Antioquia & 509 & 14 & 8 & 9.921 & 241 & 159 & 2.043 & 502 & 135 & 43 & 3 & 0 & 266 & 33 & 26 & \begin{tabular}{|l|l|}
3.393 \\
\end{tabular} & 4.123 & 3.393 \\
\hline Arauca & 96 & 2 & 2 & 442 & 11 & 13 & 310 & 44 & 12 & 0 & 1 & 0 & 12 & 2 & 0 & 144 & 161 & 144 \\
\hline \begin{tabular}{|l|} 
Atlántico \\
\end{tabular} & 85 & 3 & 3 & 1.490 & 48 & 45 & 1.209 & 212 & 84 & 11 & 1 & 0 & 2 & 2 & 1 & 464 & 626 & 464 \\
\hline \begin{tabular}{|l|} 
Barranquilla \\
\end{tabular} & 5 & 0 & 0 & \begin{tabular}{l|l|}
1.302 \\
\end{tabular} & 40 & 35 & 997 & 150 & 53 & 7 & 1 & 1 & 18 & 3 & 1 & 503 & 732 & 503 \\
\hline \begin{tabular}{|l|} 
Bogotá \\
\end{tabular} & 2 & 0 & 0 & \begin{tabular}{|l|l}
12.457 \\
\end{tabular} & 368 & 246 & 0 & 0 & 0 & 131 & 9 & 6 & 77 & 17 & 3 & 1.983 & 1.517 & 1.983 \\
\hline Bolivar & 193 & 6 & 7 & 1.312 & 38 & 33 & 1.007 & 157 & 156 & 3 & 1 & 0 & 12 & 1 & 0 & 281 & 317 & 281 \\
\hline \begin{tabular}{|l|} 
Boyacá \\
\end{tabular} & \begin{tabular}{r|}
61 \\
\end{tabular} & 1 & 1 & 3.528 & 101 & 81 & 615 & 46 & 39 & 15 & 2 & 0 & 6 & 1 & 0 & 537 & 636 & 537 \\
\hline \begin{tabular}{|l|} 
Buenaventura \\
\end{tabular} & 11 & 1 & 0 & 47 & 2 & 0 & 175 & 13 & 16 & 1 & 1 & 0 & 0 & 0 & 0 & 36 & 45 & 36 \\
\hline \begin{tabular}{|l|} 
Caldas \\
\end{tabular} & 59 & 1 & 0 & 2.272 & 61 & 43 & 545 & 42 & 56 & 7 & 2 & 0 & 7 & 1 & 0 & 798 & 885 & 798 \\
\hline \begin{tabular}{|l} 
Cali \\
\end{tabular} & 2 & 0 & 0 & 2.771 & 96 & 53 & 11.827 & 513 & 499 & 17 & 2 & 0 & 50 & 10 & 0 & 948 & \begin{tabular}{r|}
1.224 \\
\end{tabular} & 948 \\
\hline Caquetá & 147 & 2 & 3 & 545 & 20 & 16 & 1.862 & 35 & 20 & 4 & 1 & 0 & 0 & 0 & 0 & 149 & 210 & 149 \\
\hline \begin{tabular}{|l|} 
Cartagena \\
\end{tabular} & 9 & 0 & 0 & 428 & 15 & 7 & 557 & 63 & 59 & 4 & 1 & 0 & 2 & 1 & 0 & 320 & 419 & 320 \\
\hline Casanare & 126 & 4 & 1 & 832 & 25 & 29 & 1.108 & 107 & 97 & 1 & 1 & 0 & 19 & 0 & 0 & 210 & 223 & 210 \\
\hline \begin{tabular}{|l|} 
Cauca \\
\end{tabular} & 121 & 2 & 3 & \begin{tabular}{|l|l|}
3.397 \\
\end{tabular} & 101 & 68 & 1.178 & 21 & 33 & 19 & 2 & 0 & 8 & 3 & 1 & 578 & 700 & 578 \\
\hline \begin{tabular}{|l|} 
Cesar \\
\end{tabular} & 217 & $\frac{2}{6}$ & 10 & 1.213 & $\frac{1}{31}$ & 22 & 2.074 & 234 & 80 & 3 & 1 & 0 & 5 & 2 & 0 & 423 & 480 & 423 \\
\hline \begin{tabular}{|l|} 
Choco \\
\end{tabular} & 161 & 3 & 5 & 86 & 2 & 1 & 685 & 13 & 40 & 1 & 1 & 0 & 0 & 0 & 0 & 62 & 95 & 62 \\
\hline \begin{tabular}{|l|} 
Córdoba \\
\end{tabular} & 190 & 7 & 4 & 2.161 & 53 & 48 & 1.531 & 235 & 47 & 7 & 1 & 2 & 3 & 1 & 1 & 533 & 736 & 533 \\
\hline \begin{tabular}{|l} 
Cundinamarca \\
\end{tabular} & 70 & 1 & 2 & 7.478 & 193 & 182 & 3.356 & 173 & 198 & 27 & 2 & 1 & 53 & 3 & 1 & 1.209 & 1.575 & 1.209 \\
\hline \begin{tabular}{|l|} 
Guainía \\
\end{tabular} & 11 & 0 & 0 & 86 & 2 & 2 & 40 & 4 & 4 & 0 & 1 & 0 & 0 & 0 & 0 & 17 & 21 & 17 \\
\hline Guaviare & 80 & 1 & 0 & 202 & 3 & 5 & 141 & 23 & 12 & 0 & 1 & 0 & 0 & 0 & 0 & 35 & 40 & 35 \\
\hline Huila & 100 & 2 & 0 & 2.543 & 68 & 124 & 6.694 & 211 & 168 & 29 & 2 & 1 & 4 & 2 & 0 & 583 & 755 & 583 \\
\hline La Guajira & 86 & 2 & 1 & 1.089 & 26 & 15 & 393 & 77 & 8 & 3 & 1 & 0 & 2 & 0 & 0 & 172 & 212 & 172 \\
\hline \begin{tabular}{|l|} 
Magdalena \\
\end{tabular} & 94 & 3 & 4 & 1.297 & 33 & 16 & 500 & 80 & 27 & 2 & 1 & 0 & 4 & 2 & 0 & 206 & 268 & 206 \\
\hline \begin{tabular}{|l|} 
Meta \\
\end{tabular} & 211 & 4 & 4 & 1.896 & 58 & 42 & 2.563 & 318 & 113 & 5 & 1 & 0 & 3 & 2 & 0 & 473 & 559 & 473 \\
\hline Nariño & \begin{tabular}{l|l}
99 \\
\end{tabular} & 2 & 0 & 3.524 & 91 & 82 & 405 & 24 & 48 & 11 & 1 & 0 & 5 & 2 & 0 & 797 & 1.081 & 797 \\
\hline \begin{tabular}{|l|} 
Norte de Santander \\
\end{tabular} & 299 & 6 & 8 & 2.233 & 79 & 54 & 1.156 & 410 & 70 & 10 & 2 & 0 & 105 & 12 & 8 & 603 & 717 & 603 \\
\hline \begin{tabular}{|l|} 
Putumayo \\
\end{tabular} & 113 & 2 & 1 & 787 & 19 & 19 & 821 & 58 & 41 & 2 & 1 & 0 & 9 & 0 & 0 & 234 & 275 & 234 \\
\hline \begin{tabular}{|l|} 
Quindío \\
\end{tabular} & 11 & 0 & 0 & 1.574 & 45 & 39 & 521 & 142 & 54 & 6 & 1 & 0 & 4 & 2 & 0 & 395 & 487 & 395 \\
\hline Risaralda & 34 & 1 & 4 & 2.151 & 62 & 32 & 515 & 51 & 30 & 3 & 1 & 0 & 35 & 3 & 1 & 710 & 1.006 & 710 \\
\hline \begin{tabular}{|l|} 
San Andrés \\
\end{tabular} & 0 & 0 & 0 & 208 & 5 & 1 & 65 & 8 & 6 & 1 & 1 & 0 & 0 & 0 & 0 & 9 & 13 & 9 \\
\hline Santa Marta D.E. & 24 & 2 & 3 & 660 & 31 & 11 & 221 & 52 & 19 & 4 & 1 & 1 & 2 & 0 & 0 & 142 & 191 & 142 \\
\hline \begin{tabular}{|l|l|} 
Santander \\
\end{tabular} & 171 & 3 & 2 & 3.291 & 94 & 74 & 3.591 & 574 & 116 & 25 & 2 & 0 & 78 & 4 & 0 & 776 & 915 & 776 \\
\hline Sucre & $\begin{array}{ll}63 \\
63\end{array}$ & 3 & 3 & \begin{tabular}{|l|}
1.337 \\
\end{tabular} & 39 & 20 & 1.478 & 228 & 41 & 14 & 1 & 0 & 1 & 1 & 1 & 284 & 328 & 284 \\
\hline Tolima & 98 & 2 & 0 & 3.129 & 93 & 68 & 6.333 & 458 & 235 & 11 & 1 & 0 & 26 & 2 & 1 & 892 & 1.152 & 892 \\
\hline Valle & 43 & 1 & 1 & 4.221 & 122 & 81 & \begin{tabular}{|l|}
14.353 \\
\end{tabular} & 194 & 403 & 15 & 2 & 4 & 10 & 3 & 0 & 882 & \begin{tabular}{|l|}
1.117 \\
\end{tabular} & 882 \\
\hline \begin{tabular}{|l|} 
Vaupés \\
\end{tabular} & 43 & 1 & 2 & 68 & 2 & 0 & 64 & 1 & 1 & 1 & 1 & 0 & 1 & 0 & 0 & 23 & 44 & 23 \\
\hline Vichada & 39 & 1 & 0 & 142 & 3 & 5 & 47 & 8 & 4 & 0 & 1 & 0 & 0 & 0 & 0 & 19 & 20 & 19 \\
\hline \begin{tabular}{|l} 
Total nacional \\
a
\end{tabular} & 3.716 & 93 & 83 & \begin{tabular}{|l|}
82.321 \\
\end{tabular} & 2.325 & 1.776 & 71.138 & 5.497 & 3.030 & 443 & 60 & 16 & 830 & 115 & 45 & 19.865 & 23.951 & 19.865 \\
\hline
\end{tabular}

Tema central

Situación Nal.

Mortalidad

Trazadores

Brotes

COVID-19

Tablas $\underbrace{\text { instituto }}_{\substack{\text { Sacional de } \\ \text { Salud }}}$ 


\begin{tabular}{|c|c|c|c|c|c|c|c|c|c|c|c|c|c|c|c|c|c|c|}
\hline \multirow[b]{2}{*}{ Departamento } & \multicolumn{3}{|c|}{ IRAG inusitado } & \multicolumn{3}{|c|}{ Malaria } & \multicolumn{3}{|c|}{ Meningitis bacteriana } & \multicolumn{3}{|c|}{$\begin{array}{c}\text { Morbilidad por IRA consulta externay } \\
\text { urgencias }\end{array}$} & \multicolumn{3}{|c|}{$\begin{array}{c}\text { Morbilidad por IRA hospitalizaciones } \\
\text { en sala general }\end{array}$} & \multicolumn{3}{|c|}{$\begin{array}{l}\text { Morbilidad por IRA hospitalizaciones } \\
\text { en UCI }\end{array}$} \\
\hline & 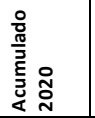 & $\begin{array}{l}\frac{0}{0} \\
\frac{0}{0} \\
\frac{0}{4} \\
\end{array}$ & 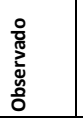 & 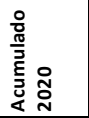 & 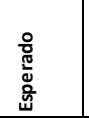 & 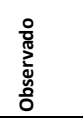 & 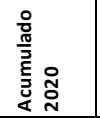 & $\begin{array}{l}\circ \\
\frac{0}{0} \\
\frac{0}{0} \\
\frac{2}{4} \\
\end{array}$ & 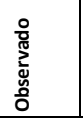 & 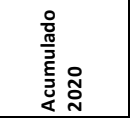 & 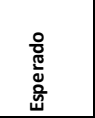 & 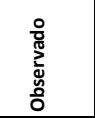 & 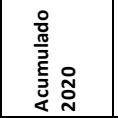 & $\begin{array}{l}\frac{0}{0} \\
\frac{0}{0} \\
\frac{0}{4} \\
\end{array}$ & 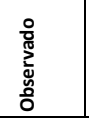 & 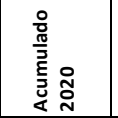 & $\begin{array}{l}\frac{0}{0} \\
\frac{0}{0} \\
\frac{0}{4} \\
\end{array}$ & $\begin{array}{l}\text { 유 } \\
\text { श्र } \\
0 \\
\text { o. }\end{array}$ \\
\hline Amazonas & 106 & 4 & 0 & 1.228 & 266 & 20 & 6 & 1 & 0 & 6.491 & 822 & 295 & 235 & 11 & 18 & 0 & 0 & 0 \\
\hline Antioquia & 1.663 & 287 & 55 & 5.975 & 509 & 465 & 65 & 19 & 9 & 518.946 & 76.782 & 41.384 & \begin{tabular}{l|}
19.439 \\
\end{tabular} & 1.987 & 2.401 & 2.540 & 55 & 460 \\
\hline Arauca & 27 & 5 & 0 & 34 & 4 & 2 & 4 & 1 & 0 & 16.632 & 2.673 & 1.522 & 585 & 105 & 97 & 11 & 4 & 0 \\
\hline Atlántico & 1.314 & 301 & 17 & 5 & 1 & 0 & 15 & 3 & 1 & 49.677 & 10.683 & 3.680 & 902 & 194 & 139 & 637 & 68 & 67 \\
\hline Barranquilla & 2.222 & 490 & 2 & 4 & 2 & 0 & 17 & 5 & 4 & 79.631 & 16.775 & 5.169 & \begin{tabular}{l|l|}
4.545 \\
\end{tabular} & 330 & 210 & 2.119 & 59 & 136 \\
\hline Bogotá & 4.615 & 769 & 16 & 9 & 1 & 0 & 93 & 20 & 12 & 848.985 & 114.517 & 52.401 & 51.648 & 4.573 & 4.983 & 14.426 & 436 & 1.864 \\
\hline Bolívar & \begin{tabular}{l|l|}
479 \\
\end{tabular} & 96 & 22 & 1.556 & 91 & 102 & 6 & 6 & 0 & \begin{tabular}{|l|}
85.905 \\
\end{tabular} & 11.705 & 7.793 & 1.109 & 221 & 72 & 40 & 0 & 5 \\
\hline \begin{tabular}{|l|} 
Boyacá \\
\end{tabular} & 106 & 16 & 0 & 1 & 1 & 0 & 14 & 5 & 4 & 63.083 & $\begin{array}{ll}13.058 \\
\end{array}$ & 7.435 & 2.457 & 323 & 238 & 250 & 17 & 47 \\
\hline Buenaventura & 0 & 0 & 0 & 813 & 108 & 126 & 5 & 1 & 1 & 10.528 & 1.231 & 542 & 296 & 0 & 21 & 53 & 0 & 17 \\
\hline Caldas & 148 & 21 & 14 & 7 & 2 & 1 & 3 & 2 & 0 & 49.450 & 8.931 & 3.300 & 1.587 & 276 & 139 & 448 & 25 & 63 \\
\hline \begin{tabular}{|l|} 
Cali \\
\end{tabular} & 3.029 & 595 & 50 & 45 & 6 & 2 & 34 & 8 & 3 & 150.147 & 21.422 & 10.942 & \begin{tabular}{|l|l|}
4.318 \\
\end{tabular} & 531 & 271 & 679 & 43 & 130 \\
\hline Caquetá & 40 & 6 & 3 & 18 & 4 & 1 & 7 & 3 & 2 & 20.760 & 4.020 & 1.438 & 916 & 120 & 152 & 165 & 1 & 104 \\
\hline Cartagena & 1.916 & 331 & 50 & 3 & 2 & 0 & 5 & 4 & 0 & 113.398 & 16.743 & 7.787 & 7.170 & 377 & 732 & 2.164 & 119 & 160 \\
\hline Casanare & 44 & 13 & 0 & 90 & 1 & 32 & 4 & 1 & 2 & \begin{tabular}{|l|}
13.415 \\
\end{tabular} & 2.681 & 1.793 & 334 & 46 & 52 & 101 & 0 & 28 \\
\hline Cauca & 469 & 78 & 12 & 3.886 & 134 & 179 & 9 & 4 & 2 & 75.710 & 9.047 & 3.578 & 1.057 & 84 & 66 & 8 & 1 & 1 \\
\hline $\begin{array}{l}\text { Cesar } \\
\end{array}$ & 755 & 129 & 134 & 21 & 2 & 1 & 4 & 3 & 1 & \begin{tabular}{ll|}
49.264 \\
\end{tabular} & \begin{tabular}{ll|}
12.221 \\
\end{tabular} & 5.140 & 3.193 & 528 & 538 & 747 & 35 & 204 \\
\hline \begin{tabular}{|l|} 
Choco \\
\end{tabular} & 295 & 84 & 27 & 16.835 & 1.408 & 1.259 & 3 & 3 & 1 & 9.214 & 1.352 & 561 & 769 & 140 & 18 & 0 & 0 & 0 \\
\hline \begin{tabular}{|l|} 
Córdoba \\
\end{tabular} & 791 & 133 & 1 & 5.332 & \begin{tabular}{r|}
287 \\
\end{tabular} & 516 & 11 & 2 & 4 & 178.272 & 14.275 & 18.811 & 1.120 & 351 & 135 & 222 & 39 & 7 \\
\hline Cundinamarca & 813 & 186 & 9 & 0 & 1 & 0 & 25 & 8 & 4 & 167.196 & 23.210 & 14.875 & 7.042 & 623 & 673 & 2.140 & 28 & 267 \\
\hline Guainía & 4 & 2 & 0 & 2.729 & 123 & 346 & 1 & 1 & 0 & 1.821 & 191 & 270 & 60 & 23 & 8 & 35 & 0 & 12 \\
\hline Guaviare & 6 & 1 & 0 & 1.486 & 88 & 56 & 1 & 1 & 0 & 4.295 & 678 & 436 & 231 & 46 & 40 & 0 & 0 & 0 \\
\hline Huila & 270 & 32 & 3 & 6 & 1 & 0 & 7 & 4 & 0 & 68.810 & 9.968 & 6.913 & 2.470 & 249 & 343 & 463 & 24 & 144 \\
\hline La Guajira & 269 & 47 & 11 & 14 & 3 & 0 & 3 & 1 & 0 & 105.656 & 12.112 & 9.581 & 4.343 & 654 & 354 & 261 & 43 & 34 \\
\hline Magdalena & 571 & 125 & 6 & 20 & 2 & 0 & 2 & 2 & 0 & 50.014 & 8.409 & 4.250 & 1.358 & 225 & 77 & 22 & 0 & 0 \\
\hline Meta & 109 & 24 & 2 & 600 & 10 & 39 & 13 & 4 & 2 & 43.138 & 6.904 & 3.837 & 1.630 & 129 & 280 & 355 & 15 & 91 \\
\hline Nariño & 321 & 83 & 2 & 13.698 & 640 & 1.044 & 23 & 8 & 2 & 81.836 & \begin{tabular}{|l|l|}
15.271 \\
\end{tabular} & 4.950 & 2.809 & 355 & 267 & 207 & 6 & 58 \\
\hline Norte de Santander & 622 & 116 & 1 & 4.379 & 102 & 205 & 27 & 4 & 7 & 95.292 & 12.269 & 10.212 & 6.593 & 632 & 644 & 935 & 26 & 138 \\
\hline \begin{tabular}{|l} 
Putumayo \\
\end{tabular} & 73 & 13 & 1 & 42 & 6 & 3 & 12 & 1 & 3 & 13.298 & 2.593 & 1.106 & 642 & 108 & 42 & 30 & 0 & 1 \\
\hline Quindío & 71 & 14 & 0 & 4 & 1 & 1 & 5 & 1 & 0 & 36.340 & 5.865 & 3.222 & 1.081 & 260 & 68 & 121 & 11 & 31 \\
\hline Risaralda & 96 & 11 & 1 & 613 & 49 & 58 & 11 & 4 & 1 & 61.269 & 9.151 & 5.670 & 1.644 & 230 & 227 & 283 & \begin{tabular}{|l|l}
9 \\
\end{tabular} & 74 \\
\hline San Andrés & 16 & 3 & 0 & 0 & 0 & 0 & 0 & 0 & 0 & 3.666 & 739 & 176 & 335 & 85 & 16 & 1 & 0 & 1 \\
\hline Santa Marta D.E. & 454 & 105 & 7 & 0 & 1 & 0 & 7 & 1 & 1 & 17.737 & 2.186 & 1.567 & 1.044 & 156 & 109 & 370 & 19 & 64 \\
\hline Santander & 278 & 44 & 8 & 10 & 3 & 0 & 17 & 8 & 3 & 117.950 & 14.835 & 9.519 & 11.130 & 821 & 1.180 & 1.834 & 97 & 246 \\
\hline Sucre & 444 & 127 & 5 & 26 & 3 & 2 & 7 & 2 & 1 & \begin{tabular}{|l|}
44.838 \\
\end{tabular} & 9.158 & 3.384 & $\begin{array}{l}3.189 \\
\end{array}$ & 781 & 390 & 786 & 72 & 69 \\
\hline Tolima & 239 & 46 & 3 & 0 & 1 & 0 & 23 & 4 & 3 & 88.049 & 10.765 & 7.648 & 2.569 & 263 & 421 & 861 & 58 & 196 \\
\hline $\begin{array}{l}\text { Valle } \\
\end{array}$ & 1.152 & 221 & 19 & 44 & 8 & 4 & 21 & 8 & 1 & \begin{tabular}{ll|l|}
88.078 \\
\end{tabular} & 12.475 & 8.045 & 2.341 & 204 & 281 & 653 & 1 & 150 \\
\hline Vaupés & 1 & 0 & 0 & 86 & \begin{tabular}{l|l}
35 \\
\end{tabular} & 8 & 3 & 1 & 0 & 988 & 238 & 134 & 27 & 8 & 0 & 0 & 0 & 0 \\
\hline Vichada & 8 & 2 & 0 & 2.645 & 77 & 166 & 3 & 1 & 0 & 2.195 & 352 & 194 & 100 & 9 & 21 & 29 & 0 & 11 \\
\hline Total nacional & 23.836 & 4.549 & \begin{tabular}{|l|l|}
481 & \\
4
\end{tabular} & 62.264 & \begin{tabular}{|l|l|}
3.983 \\
\end{tabular} & 4.638 & 516 & 155 & 74 & 3.431 .974 & 496.296 & 269.560 & 152.318 & 16.050 & 15.723 & 33.996 & \begin{tabular}{l|l|}
1.305 \\
\end{tabular} & 4.880 \\
\hline
\end{tabular}

Tema central

Situación Nal.

Mortalidad

Trazadores

Brotes

COVID-19

Tablas

2 instituto 


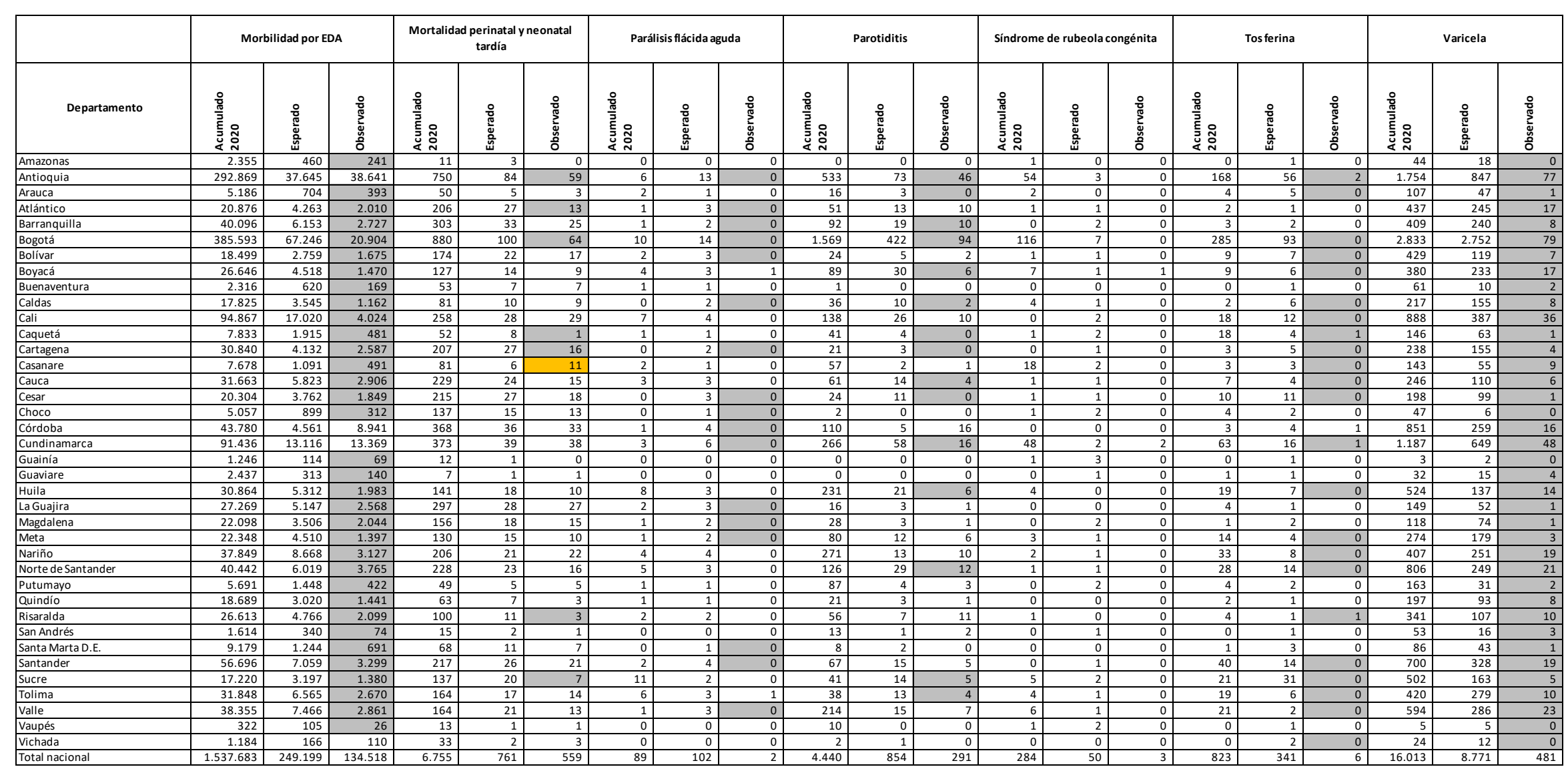




\section{Comportamiento de la notificación por departamento a semana 41}

\begin{tabular}{|c|c|c|c|c|c|c|c|c|c|c|c|c|c|c|c|c|}
\hline \multirow[b]{2}{*}{ Departamento } & \multicolumn{2}{|c|}{ Chagas agudo } & \multicolumn{2}{|c|}{ Chikungunya } & \multicolumn{2}{|c|}{ Difteria } & \multicolumn{2}{|c|}{$\begin{array}{c}\text { Enfermedad por virus } \\
\text { Zika }\end{array}$} & \multicolumn{2}{|c|}{ Leishmaniasis } & \multicolumn{2}{|c|}{ Leptospirosis } & \multicolumn{2}{|c|}{ Mortalidad materna } & \multicolumn{2}{|c|}{$\begin{array}{c}\text { Mortalidad por IRA en } \\
\text { menores de } 5 \text { años }\end{array}$} \\
\hline & 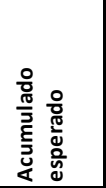 & 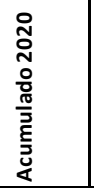 & 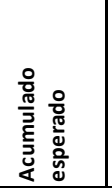 & 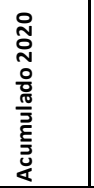 & 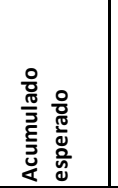 & 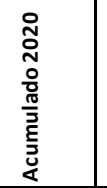 & 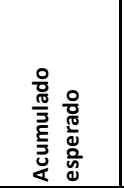 & 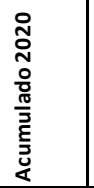 & 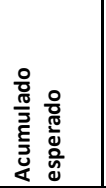 & 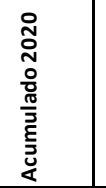 & 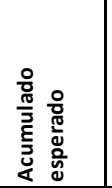 & 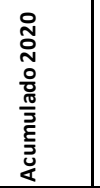 & 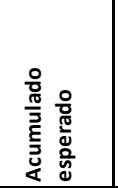 & 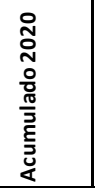 & 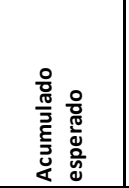 & 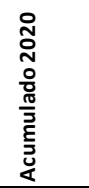 \\
\hline Amazonas & 0 & 0 & 4 & 3 & 0 & $\begin{array}{l} \\
\end{array}$ & 6 & 3 & 13 & 1 & 8 & 1 & 1 & 3 & 2 & 3 \\
\hline \begin{tabular}{|l|} 
Antioquia \\
\end{tabular} & 1 & 0 & 39 & 7 & 2 & 1 & 24 & 7 & 1.169 & 819 & 368 & 235 & 24 & 23 & 61 & 21 \\
\hline \begin{tabular}{|l|} 
Arauca \\
\end{tabular} & 1 & 1 & 4 & 0 & 0 & 1 & 8 & 2 & 13 & 6 & 8 & 2 & 2 & 1 & 2 & 4 \\
\hline Atlántico & 2 & 0 & 13 & 0 & 0 & 0 & 13 & 3 & 2 & 2 & 31 & 31 & 10 & 15 & 7 & 6 \\
\hline \begin{tabular}{|l|} 
Barranquilla \\
\end{tabular} & 0 & 0 & 11 & 1 & 0 & 0 & 13 & 1 & 2 & 1 & 43 & 37 & 7 & 16 & 9 & 10 \\
\hline \begin{tabular}{|l|} 
Bogotá \\
\end{tabular} & 2 & 0 & 0 & 1 & 2 & 6 & 6 & 18 & 0 & 0 & 35 & 27 & 20 & 22 & 59 & 28 \\
\hline \begin{tabular}{|l|} 
Bolívar \\
\end{tabular} & 1 & 0 & 4 & 2 & 0 & 0 & 5 & 1 & 262 & 243 & 56 & 35 & 6 & 9 & 18 & 5 \\
\hline Boyacá & 3 & 0 & 4 & 1 & 0 & 0 & 3 & 4 & 98 & 37 & 11 & 7 & 5 & 4 & 4 & 8 \\
\hline Buenaventura & 0 & 0 & 2 & 0 & 0 & 0 & 1 & 0 & 30 & 12 & 26 & 24 & 4 & 3 & 4 & 5 \\
\hline Caldas & 0 & 0 & 7 & 2 & 0 & 0 & 7 & 0 & 143 & 171 & 10 & 12 & 2 & 4 & 4 & 0 \\
\hline Cali & 0 & 0 & 64 & 15 & 1 & 0 & 339 & 28 & 9 & 2 & 97 & 96 & 6 & 9 & 12 & 11 \\
\hline Caquetá & 1 & 0 & 11 & 2 & 0 & 0 & 3 & 10 & 203 & 122 & 8 & 5 & 4 & 6 & 6 & 3 \\
\hline \begin{tabular}{|l|} 
Cartagena \\
\end{tabular} & 0 & 0 & 7 & 3 & 0 & 0 & 10 & 1 & 1 & 1 & 14 & 11 & 7 & 8 & 15 & 9 \\
\hline \begin{tabular}{|l|} 
Casanare \\
\end{tabular} & 10 & 7 & 19 & 3 & 0 & 0 & 25 & 3 & 9 & 3 & 15 & 13 & 1 & 4 & 2 & 3 \\
\hline Cauca & 0 & 0 & 4 & 3 & 0 & 0 & 5 & 2 & 85 & 61 & 25 & 42 & 8 & 11 & 8 & 5 \\
\hline Cesar & 2 & 0 & 4 & 1 & 1 & 2 & 13 & 0 & 26 & 28 & 26 & 28 & 9 & 9 & 17 & 7 \\
\hline \begin{tabular}{|l|} 
Choco \\
\end{tabular} & 0 & 0 & 2 & 1 & 0 & 0 & 1 & 1 & 310 & 135 & 46 & 25 & 9 & 10 & 25 & 20 \\
\hline Córdoba & 1 & 0 & 5 & 0 & 0 & 0 & 14 & 1 & 109 & 67 & 22 & 14 & 14 & 16 & 13 & 10 \\
\hline Cundinamarca & 1 & 0 & 49 & 27 & 0 & 0 & 33 & 22 & 190 & 56 & 40 & 33 & 12 & 24 & 19 & 7 \\
\hline Guainía & 0 & 0 & 1 & 0 & 0 & 0 & 1 & 0 & 41 & 5 & 3 & 9 & 1 & 1 & 2 & 0 \\
\hline Guaviare & 0 & 0 & 19 & 0 & 0 & 0 & 4 & 0 & 307 & 248 & 30 & 8 & 1 & 0 & 2 & 3 \\
\hline Huila & 0 & 0 & 34 & 4 & 0 & 0 & 19 & 1 & 32 & 13 & 41 & 50 & 3 & 1 & 5 & 10 \\
\hline La Guajira & 0 & 0 & 2 & 1 & 1 & 0 & 2 & 0 & 35 & 8 & 8 & 6 & 19 & 31 & 30 & 24 \\
\hline Magdalena & 1 & 0 & 1 & 0 & 0 & 0 & 2 & 0 & 5 & 6 & 10 & 3 & 9 & 16 & 14 & 9 \\
\hline \begin{tabular}{|l|} 
Meta \\
\end{tabular} & 2 & 0 & 32 & 6 & 0 & 0 & 27 & 5 & 451 & 130 & 14 & 7 & 5 & 9 & 11 & 13 \\
\hline Nariño & 0 & 0 & 1 & 1 & 0 & 0 & 2 & 2 & 502 & 154 & 17 & 7 & 11 & 9 & 10 & 12 \\
\hline Norte de Santander & 1 & 6 & 15 & 0 & 1 & 3 & 54 & 3 & 434 & 135 & 10 & 11 & 9 & 13 & 8 & 12 \\
\hline Putumayo & 0 & 1 & 47 & 12 & 0 & 0 & 56 & 3 & 162 & 89 & 7 & 10 & 2 & 5 & 5 & 2 \\
\hline Quindío & 0 & 0 & 8 & 8 & 0 & 1 & 4 & 0 & 1 & 0 & 26 & 29 & 1 & 1 & 5 & 4 \\
\hline \begin{tabular}{|l|} 
Risaralda \\
\end{tabular} & 0 & 0 & 25 & 9 & 0 & 0 & 13 & 6 & 254 & 100 & 69 & 116 & 3 & 3 & 6 & 7 \\
\hline \begin{tabular}{|l|} 
San Andrés \\
\end{tabular} & 0 & 0 & 1 & 0 & 0 & 0 & 2 & 0 & 0 & 0 & 1 & 0 & 0 & 0 & 0 & 0 \\
\hline \begin{tabular}{|l|} 
Santa Marta D.E. \\
\end{tabular} & 1 & 0 & 5 & 1 & 0 & 0 & 6 & 0 & 11 & 4 & 6 & 6 & 4 & 8 & 3 & 3 \\
\hline \begin{tabular}{|l|} 
Santander \\
\end{tabular} & 5 & 3 & 60 & 11 & 0 & 0 & 79 & 6 & 516 & 350 & 31 & 29 & 6 & 9 & 8 & 6 \\
\hline \begin{tabular}{|l|} 
Sucre \\
\end{tabular} & 1 & 1 & 6 & 2 & 0 & 0 & 10 & 2 & 42 & 28 & 19 & 29 & 8 & 9 & 11 & 7 \\
\hline Tolima & 3 & 0 & 85 & 25 & 0 & 0 & 55 & 22 & 958 & 333 & 197 & 170 & 7 & 3 & 11 & 8 \\
\hline \begin{tabular}{|l|} 
Valle \\
\end{tabular} & 0 & 0 & 19 & 6 & 0 & 0 & 97 & 4 & 39 & 13 & 184 & 209 & 5 & 6 & 7 & 4 \\
\hline \begin{tabular}{|l|} 
Vaupés \\
\end{tabular} & 0 & 0 & 1 & 0 & 0 & 0 & 2 & 0 & 36 & 30 & 1 & 0 & 1 & 1 & 2 & 1 \\
\hline Vichada & 0 & 0 & 0 & 0 & 0 & 0 & 3 & 0 & 49 & 25 & 2 & 2 & 5 & 1 & 5 & 4 \\
\hline Total nacional & 39 & 19 & 614 & 158 & 8 & 14 & 968 & 161 & \begin{tabular}{l|}
6.549 \\
\end{tabular} & 3.438 & 1.565 & 1.379 & 251 & 323 & 432 & 294 \\
\hline
\end{tabular}

Tema central

Situación Nal.

Mortalidad

Trazadores

Brotes

COVID-19

Tablas 2 instrTuto 


\section{Semana epidemiológica 41}

4 al 10 de octubre de 2020

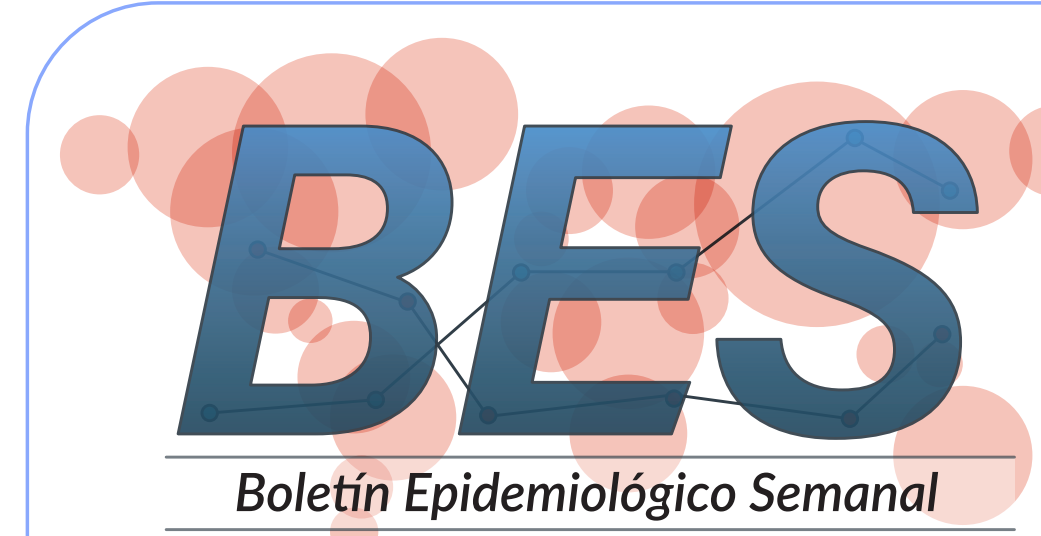

Boletín Epidemiológico Semanal

Dra. Martha Lucia Ospina Martínez
Directora General INS
Dr. Franklyn Edwin Prieto Alvarado
Dra. Diana Walteros
Subdirector de Vigilancia y Análisis del Riesgo en Salud Pública de Prevención Vigilancia y Control en Salud Pública
Dr. Hernán Quijada Bonilla
Subdirector de Análisis del Riesgo y Respuesta inmediata
Una publicación del:
Instituto Nacional de Salud
Publicación en línea: ISSN 2357-6189
https://doi.org/10.33610/23576189.2020.41
2020

Asistencia técnica de:

Bloomberg
Philanthropies

\section{Expertos Temáticos}

Situación Nacional

Grupo Sivigila sivigila@ins.gov.co

Mortalidad

Jankrique@ins.gov.co

Grace Alejandra Avila gavilam@ins.gov.co

Eventos Trazadores

Diana Carolina Malo_dmalo@ins.gov.co

Carolina ferro cferro@ins.gov.co

Maria Angelica Avila mavila@ins.gov.co

Brotes

Gestor sistema de alerta temprana eri@ins.gov.co

Jorge Diaz jdiaz@ins.gov.co

Tablas de mando

Yudy Silva Lizarazoysilva@ins.gov.co

Yudy Silva Lizarazoysilva@ins.go

Edición

Dr. Hernán Qujiada Bonilla hquijada@ins.gov.co

Diseño y diagramación

AlexanderCasas acasasc@ins.gov.co

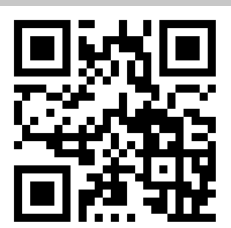

Conozca más en www.ins.gov.co ㅁ.

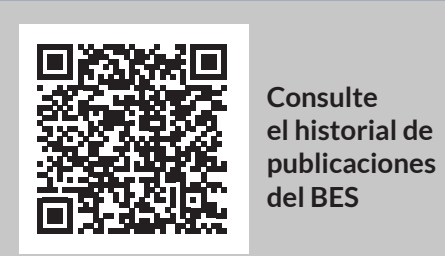

